\title{
UCRL-TR-227766-REV-1
}

LAW RENCE LIVERMORE N A T IO N A L LABORATORY

Mode-of-Action Uncertainty for Dual-Mode Carcinogens: A Bounding Approach for Naphthalene-Induced Nasal Tumors in Rats Based on PBPK and 2-Stage Stochastic Cancer Risk Models

K. T. Bogen

May 15, 2007 
This document was prepared as an account of work sponsored by an agency of the United States Government. Neither the United States Government nor the University of California nor any of their employees, makes any warranty, express or implied, or assumes any legal liability or responsibility for the accuracy, completeness, or usefulness of any information, apparatus, product, or process disclosed, or represents that its use would not infringe privately owned rights. Reference herein to any specific commercial product, process, or service by trade name, trademark, manufacturer, or otherwise, does not necessarily constitute or imply its endorsement, recommendation, or favoring by the United States Government or the University of California. The views and opinions of authors expressed herein do not necessarily state or reflect those of the United States Government or the University of California, and shall not be used for advertising or product endorsement purposes.

This work was performed under the auspices of the U.S. Department of Energy by University of California, Lawrence Livermore National Laboratory under Contract W-7405-Eng-48. 


\title{
Mode-of-Action uncertainty for dual-mode carcinogens:
}

\section{A bounding approach for naphthalene-induced nasal tumors in rats based on PBPK and 2-stage stochastic cancer risk models}

Report to DOE-OakRidge Associated Universities (Funding Agreement \#: 5-15235, Agreement ID \#: 1024435, Proposal \#: D11248), "EPA Project 06-08, Uncertainty White Papers (Bogen)"

\author{
by
}

Kenneth T. Bogen, DrPH ${ }^{1}$

January 30, 2007

Revised: May 13, 2007

This work was performed under auspices of the U.S. Department of Energy by University of California, Lawrence Livermore National Laboratory (LLNL) under Contract W-7405-Eng-48, with support from the U.S. Environmental Protection Agency through DOE-OakRidge Associated Universities (Agreement 1024435).

${ }^{1}$ Corresponding address: Energy \& Environment Directorate L-396, 7000 East Ave., Livermore, CA 94550; Tel.: (925) 422-0902; fax: (925) 424-3255; E-mail: bogen@,LLNL.gov 


\section{Abstract}

A relatively simple, quantitative approach is proposed to address a specific, important gap in the approach recommended by the USEPA Guidelines for Cancer Risk Assessment to address uncertainty in carcinogenic mode of action of certain chemicals when risk is extrapolated from bioassay data. These Guidelines recognize that some chemical carcinogens may have a site-specific mode of action (MOA) that is dual, involving mutation in addition to cell-killing induced hyperplasia. Although genotoxicity may contribute to increased risk at all doses, the Guidelines imply that for dual MOA (DMOA) carcinogens, judgment be used to compare and assess results obtained using separate "linear" (genotoxic) vs. "nonlinear" (nongenotoxic) approaches to low-level risk extrapolation. However, the Guidelines allow the latter approach to be used only when evidence is sufficient to parameterize a biologically based model that reliably extrapolates risk to low levels of concern. The Guidelines thus effectively prevent MOA uncertainty from being characterized and addressed when data are insufficient to parameterize such a model, but otherwise clearly support a DMOA. A bounding factor approach-similar to that used in reference dose procedures for classic toxicity endpoints - can address MOA uncertainty in a way that avoids explicit modeling of low-dose risk as a function of administered or internal dose. Even when a "nonlinear" toxicokinetic model cannot be fully validated, implications of DMOA uncertainty on low-dose risk may be bounded with reasonable confidence when target tumor types happen to be extremely rare. This concept was illustrated for a likely DMOA rodent carcinogen naphthalene, specifically to the issue of risk extrapolation from bioassay data on naphthalene-induced nasal tumors in rats. Bioassay data, supplemental toxicokinetic data, and related physiologically based pharmacokinetic and 2-stage stochastic carcinogenesis modeling results all clearly indicate that naphthalene is a DMOA carcinogen. Plausibility bounds on rat-tumor-type specific DMOA-related uncertainty were obtained using a 2-stage model adapted to reflect the empirical link between genotoxic and cytotoxic effects of the most potent identified genotoxic naphthalene metabolites, 1,2- and 1,4-naphthoquinone. Bound-specific "adjustment" factors were then used to reduce naphthalene risk estimated by linear extrapolation (under the default genotoxic MOA assumption), to account for the DMOA exhibited by this compound. 


\section{Introduction}

This white paper aims to (1) point out how the Guidelines for Cancer Risk Assessment (USEPA, 2005) currently impedes quantitative characterization of uncertainty in carcinogenic mode of action (MOA) for chemical carcinogens that act by more than one mechanism, (2) propose a method to characterize and address MOA uncertainty in this situation, and (3) illustrate the application of the proposed method to the case of naphthalene. Specifically, a relatively simple, quantitative approach is proposed to address a specific, important gap in the approach recommended by the USEPA Guidelines for Cancer Risk Assessment to address uncertainty in carcinogenic mode of action of certain chemicals when risk is extrapolated from bioassay data. The scope of this paper does not extend to the broader question of how to integrate this specific source of model uncertainty into a comprehensive characterization of all sources of uncertainty in estimated cancer potency or risk. Such a comprehensive uncertainty characterization is not required in order to apply the proposed method, which may be implemented by straightforward extension of standard uncertainty-factor procedures already in use.

Current multistage cancer theory and the Guidelines for Cancer Risk Assessment (USEPA, 2005) recognize that a chemical carcinogen may have a site-specific mode of action (MOA) that is dual, involving mutation in addition to cell-killing induced hyperplasia, and that in such a case the relative contributions of each mode to increased risk may change as a function of dose. In contrast, the Guidelines suggest that "linear" vs. "nonlinear" approaches to risk extrapolation are dichotomous, and they vaguely recommend that in ambiguous cases, judgment should be used to compare and assess results obtained using "both" of these two approaches (see Appendix). Notably, the Guidelines are unclear about exactly how MOA uncertainty should be characterized and addressed when available bioassay and supplemental mechanistic toxicokinetic data for a given tumor site happen to meet the following conditions:

- the data clearly support a dual MOA (DMOA),

- $\quad$ the data establish with reasonable certainty that the default "linear" extrapolation procedure is not scientifically plausible (without at least some modification to reflect the nongenotoxic MOA exhibited by the data), but nevertheless

- $\quad$ the data are insufficient to parameterize a biologically based model that reliably extrapolates human (or bioassay animal) risk to very low, environmentally relevant levels of exposure. 
The Guidelines do not clearly specify how to treat such a case, because they characterize such a DMOA case as "ambiguous" and recommend it be addressed only by either (or both) of two quite different dose-response extrapolation procedures: linear extrapolation for "genotoxic" carcinogens, and traditional nonlinear uncertainty-factor methodology for "nongenotoxic" carcinogens. Specifically, the Guidelines recommend that "If there are multiple modes of action at a single tumor site, one linear and another nonlinear, then both approaches are used to decouple and consider the respective contributions of each mode of action in different dose ranges" (see Appendix). The "catch-22" is that, for nongenotoxic carcinogens, the Guidelines elsewhere allow this recommendation to be pursued only when available data either (a) clearly demonstrate that an exclusively nongenotoxic MOA is applicable, or (b) establish and validate a comprehensive toxicokinetic model applicable to the carcinogen in question. Option (a) is by definition inapplicable to any DMOA carcinogen, and a comprehensive toxicokinetic model to pursue option (b) has not yet been accepted for regulatory application to any carcinogen (with a DMOA, or any other MOA). To pursue option (b), the Guidelines appear to require that a biologically based a toxicokinetic model be validated for application at all dose levels, before any consideration may be given to any of its logical implications that are based on convincing mechanistic data.

For example, suppose histological evidence from a positive chemical carcinogen bioassay indicated unambiguously that dose-related cell-killing had induced regenerative hyperplasia at multiple sites of tumorigenesis in cells histologically related to, and plausibly precursors of, dose-related tumors of types $i$ each observed to occur at a rate $R_{i}$ significantly elevated above its corresponding background tumor rate $\left(r_{\mathrm{i}}\right)$. Further assume that no tumor types were significantly elevated other than those also associated in each case with histologically related hyperplasia, that the chemical is known from in vitro and in vivo studies to be cytotoxic particularly to cells of types that occur at only sites of observed dose-related tumorigenesis, and that species- and sitespecific cytotoxicity of the compound is predicted by detailed and validated physiologically based pharmacokinetic (PBPK) modeling. Based on current mechanistic-multistage cancer theory (e.g., Moolgavkar, 1983; Bogen, 1989), the observed dose-induced, histologically linked regenerative hyperplasia would almost certainly have contributed to amplification of $R_{i}$, albeit by unknown relative site-specific factors $F_{\mathrm{h}}$, where $F_{\mathrm{h}} \leq R_{i} / r_{i}$. Absent evidence of genotoxicity by the test chemical or any of its metabolites, it could be argued that this chemical has a 
nongenotoxic MOA with $F_{\mathrm{h}}=R_{i} / r_{i}$. Now we add a final assumption that the chemical involved and/or its metabolite(s) is known to be genotoxic. Even with this final assumption, it still would be scientifically implausible to claim $F_{\mathrm{h}}=1$, given the assumed histological and mechanistic evidence. While the evidence that $F_{\mathrm{h}}>1$ is convincing in this hypothetical case, the magnitude by which $F_{\mathrm{h}}$ is $>1$ remains uncertain. A biologically based 2-stage "MVK" or "cell kinetic" type of cancer model could in this case realistically reflect the high likelihood that both genotoxic and hyperplastic (nongenotoxic) MOAs act jointly, via a DMOA, to produce the observed response (Moolgavkar, 1983; Bogen, 1989).

Within this MVK-type modeling framework, dose-induced regenerative cell renewal may act to boost the net rate of proliferation (birth minus death/differentiation) of surviving (and typically more resistant) premalignant cells exposed to a cytotoxic agent. The number of premalignant-cell populations depends in turn on the background rate of critical mutations in these (and normal stem) cells that, together with the background net-proliferation rate, determine the spontaneous risk of tumor occurrence. How cytotoxicity and consequent regenerative cell renewal affect tumor risk thus depends critically on how exposure affects the balance of these contributing processes. Unless a cytotoxic exposure is very large and/or chronic. Although regenerative hyperplasia alone (a purely cytotoxic MOA) may often fail to boost these processes enough to increase tumor rates detectably in typical bioassay studies, it is well recognized to be effective in certain cases. Repeated or chronic administration of carbon tetrachloride very likely has a purely cytotoxic MOA, greatly amplified via magnifying the background mutation rate by prior administration of a single, initiating dose of a potent mutagen like diethylnitrosamine, aflatoxin or ionizing radiation (Solt et al., 1983; Brunius, 1987; Bogen, 1990; Columbano et al., 1990; Kotsanis and Metcalfe, 1991). A similar argument be made for other carcinogens that (due to cytotoxic or other mechanisms) induce sustained cell proliferation and/or suppress apoptosis, but that have at best very weak in vivo genotoxicity, such as: catechol; chloroform; chronic infection by certain microbes such Helicobacter pylori); peroxisome proliferators such as di(2-ethylhexyl-phthalate (DEHP); agents such as d-limonene and unleaded gasoline that induce adducted- $\alpha 2 \mathrm{u}$-globulin-mediated hyaline-droplet-induced nephrotoxicity and cell proliferation in male rats; sesamol; sodium saccharin and other agents that can induce bladder-irritating urinary calculi; and the mitogenic promoter 12-o-tetradecanoyl phorbol-13-acetate (TPA) (Cohen and Ellwein, 1990,1991; Dietrich and Swenberg, 1991; USEPA, 1991,2003; Rodgers and Baetcke, 
1993; Larson et al., 1994; IARC, 2003; Holmes and Rainsford, 2002; Solnick and Schauer, 2001). Thus, in the case of BHA, an expert working group concluded that "For some carcinogens not known to be genotoxic ..., irritation leading to enhanced and sustained cell proliferation may be essential for tumour development. ... Non-DNA reactive agents such as butylated hydroxyanisole appear to cause forestomach tumours primarily through initial cytotoxicity and subsequent sustained cell proliferation and hyperplasia” (IARC, 2003).

Of course, there is by definition no increased tumor risk associated with cells that are killed by a cytotoxic agent, which occurs more readily if premalignant cells have no selective advantage (e.g., via reduced metabolic-activating capability, enhanced levels of GHS or other detoxifying activity, etc.) over their normal neighbors, as may be the case for certain directacting toxicants and for ionizing radiation. For this reason, "cell proliferation is not necessarily a tumor promoter or cocarcinogen" (Melnick et al., 1996; Ward et al., 1993) and regenerative hyperplasia is not always associated with increased tumor risk. Nevertheless, it has long been well recognized that sustained cell proliferation may contribute to tumor development caused by chronic chemical exposures that are both genotoxic and cytotoxic (Schulte-Hermann et al., 1983; Ward et al., 1993; IARC, 2003) - i.e., that values of $F_{\mathrm{h}}>1$ can and do occur - as illustrated by the effectiveness of initiation-promotion protocols, and by DMOA carcinogens, including tissuespecific or contact irritants that can also damage DNA, such as formaldehyde (Conolly et al., 2004), ethyl acrylate (Ghanayem et al., 1986; Ciaccio et al., 1998), vinyl acetate (Hengstler et al., 2003), tetranitromethane (TNM) (Bucher et al., 1991; Murata et al., 1996) and, as proposed here, naphthalene.

For DMOA carcinogens, the Guidelines recommend that "An analysis of model uncertainty can be used to determine the range where extrapolation using the toxicodynamic model is supported and where further extrapolation would be based on either a linear or a nonlinear default, as appropriate" (see Appendix). This recommendation begs the question of how to avoid the "catch-22" problem described above. Specifically, the Guidelines imply that even when clear evidence that a DMOA is operative, its mechanistic basis and entire doseresponse must be understood completely - a virtually impossible task, without solving the general puzzle of cancer itself-before evidence of that DMOA will be reflected in the doseresponse model actually applied by EPA for risk assessment (although associated uncertainty 
may be "explored" by modeling). Consequently, risk assessments for DMOA carcinogens may lack scientific credibility.

While the Guidelines for Carcinogen Risk Assessment offer no clear solution to this dilemma, there is ample precedent to address it reasonably and explicitly—without requiring virtually insurmountable hurdles in the form of exhaustively validated toxicokinetic modelsusing standard procedures from the USEPA "reference dose" process (USEPA, 2002), when available evidence so warrants. In the hypothetical case above, for example, such an approach might be warranted in the special circumstance that all relevant background tumor rates are extremely small (e.g., $<10^{-3}$ ). In this circumstance, despite the fact that available toxicokinetic data might be insufficient to fully validate a toxicokinetic model applicable to environmental levels of risk extrapolation, those data could be sufficient to conclude with reasonable certainty that linear risk extrapolation assuming a fully genotoxic MOA from a "point of departure" derived from bioassay data will substantially overestimate (e.g., by $\geq 2$-fold) true incremental risk at very low doses. One context in which such reasonable certainty can arise is proposed here, namely, when:

(I) histological evidence confirms that observed tumor response rates at all dose levels of each positive bioassay have almost certainly been augmented by dose-related, histologically associated (e.g., cell-killing induced regenerative) hyperplasia, and

(II) supplemental toxicokinetic data establish that any dose-related genotoxicity is invariably accompanied by similar hyperplasia reasonably expected to amplify any purely genotoxic tumor risk, according to a biologically based multistage (e.g., MVK) model parameterized in a way constrained to reflect the maximum genotoxic tumor risk that is plausible conditional on all relevant data.

If conditions I and II hold in this hypothetical case, it should be possible to estimate from the constrained MVK model the minimum plausible factor, $\operatorname{Min}\left(F_{\mathrm{h}}\right)$, by which linear genotoxic extrapolation overestimates the true low-dose cancer risk that is consistent with the available data.

Along these lines, it is proposed that low-dose risk implications of DMOA uncertainty can be addressed using mechanistic toxicokinetic models that incorporate physiologically based pharmacokinetic (PBPK) and 2-stage stochastic carcinogenesis (MVK) model components, which in turn are sufficiently general to reflect a DMOA assumption. Specifically, in the special 
case when all relevant target tumor types happen to be extremely rare, evidence may be sufficient to characterize and address DMOA uncertainty in particular, and its low-dose implications for risk extrapolation, with reasonable confidence based on mechanistic modeling. Here, this idea is applied to the carcinogen naphthalene, which EPA recently proposed to reclassify based on NTP bioassay data indicating increased risk of very rare nasal tumors in rats, in addition to earlier NTP and other data indicating increased risk of lung tumors in mice (USEPA, 1998, 2004). Specifically, the proposed method to address MOA uncertainty for DMOA carcinogens is applied to risk extrapolation from bioassay data on naphthalene-induced tumors in rats. To do so, this illustrative application

(1) combines bioassay and in vitro data with PBPK modeling results to show with high confidence that naphthalene is a DMOA carcinogen (see Section 2.1);

(2) obtains plausibility bounds on rat-tumor-type specific DMOA-related uncertainty, using an MVK model parameterized to reflect in vitro data that link genotoxic and cytotoxic action of 1,2- and 1,4-naphthoquinone (the most potent identified genotoxic naphthalene metabolites); and

(3) derives, from plausibility bounds obtained in step (2), corresponding "adjustment" factors $<1$ appropriate to apply to naphthalene risks that are estimated more conservatively by linear extrapolation under the default genotoxic MOA assumption.

To address step (1), key bioassay and toxicokineitc data were reviewed and recently developed PBPK models for naphthalene were applied to assess a mechanistic basis for site- and speciesspecific target-organ cytotoxicity. MVK modeling results are next presented that incorporate in vitro data relating naphthalene mutagenic to cytotoxic potency. The MVK modeling results were then used to obtain corresponding "adjustment" factors by which estimates of naphthalene risk based on linear extrapolation under a default genotoxic MOA assumption should be reduced in order to reflect the likely dual MOA (DMOA) for naphthalene carcinogenicity. Each of the steps above is discussed in the corresponding sections below.

All calculations reported below were performed using Mathematica $5.0^{\circledR}$ software (Wolfram, 1999), using methods described below. 


\section{Mode of Carcinogenic Action for Naphthalene}

Key data are reviewed here concerning the ability of naphthalene to induce cancer in rodents (Section 2.1); concerning naphthalene metabolism and related cytotoxicity (Section 2.2); and concerning genotoxicity of naphthalene and its metabolites, and its relation to associated cytotoxicity (Section 2.3). Recently developed PBPK models for naphthalene are applied in Section 2.4 to assess a mechanistic basis for site- and species-specific target-organ cytotoxicity of this compound, in light of information reviewed in Sections $2.1-2.3$. Information from Sections 2.1-2.4 are then used to infer a MOA for naphthalene-induced rat nasal tumors in Section 2.5.

\subsection{Naphthalene Carcinogenicity}

Case reports of cancer in naphthalene-exposed humans involve four laryngeal cancer cases among smokers in workers at an East German naphthalene purification plant (Kup, 1978; Wolf, 1976, 1978), and a series of 11 colorectal carcinoma patients 18 to 30 years old admitted to a Nigerian hospital, "half" of whom "gave a definitive history of ingesting" the "naphthalene compound" kafura used as part of "local indigenous treatment for 'piles' or any anorectal problem" (Ajao et al., 1988). These case reports have been considered insufficient to evaluate human carcinogenicity of naphthalene (USEPA, 1998, 2004; IARC, 2002). Incidences of alveolar/bronchiolar adenomas or carcinoma were increased in female (but not male) B6C3F1 mice exposed to 30 (but not to 10) ppm naphthalene for 2 years (NTP, 1992; Abdo et al., 1992). A previous study found increased tumor multiplicity in tumor-bearing $\mathrm{A} / \mathrm{J}$ strain mice exposed to 10 or 30 ppm for 6 months (Adkins et al., 1986). More recently, increased incidences of rare respiratory epithelial adenomas and of rare olfactory epithelial neuroblastomas were observed in female rats, and rare respiratory epithelial adenomas were observed in male rats, exposed to naphthalene vapor concentrations of 10, 30, or 60 ppm for 2 years (NTP, 2000; Abdo et al., 2001; Long et al., 2003).

The U.S. Environmental Protection Agency (EPA) classified naphthalene as a possible human carcinogen (Group C, inadequate human and limited animal data), concluding that its human carcinogenic potential could not be determined from available suggestive rodent tumor data, and that "it appears unlikely that naphthalene represents a genotoxic carcinogen" (USEPA, 1998). The International Agency for Cancer Research (IARC) classified naphthalene as a 2B 
carcinogen (possibly carcinogenic to humans) based on the inhalation bioassay data in animals noted above (IARC, 2002). The EPA subsequently proposed to reclassify potential human carcinogenicity of naphthalene from "possible" to "likely" and has developed corresponding linear no-threshold risk extrapolations (USEPA, 2004). The latter proposal presumed, in accordance with default carcinogen risk assessment guidelines (USEPA, 2005), that combined data from lifetime bioassays of cancer induced in B6C3F1 mice and F344/N rats exposed chronically to naphthalene by inhalation (NTP, 1992, 2000) are plausibly consistent with an exclusively or predominantly genotoxic MOA. Current bioassay data thus clearly establish that chronic inhalation of naphthalene can induce respiratory tract tumors in rodents. However, classification of naphthalene "carcinogenicity" per se begs the question concerning the nature of low-dose dose-response for naphthalene-induced cancer risk either to humans or to rodents.

Alveolar/bronchiolar adenomas (and one carcinoma) were significantly increased by chronic inhalation of $30 \mathrm{ppm}$ (but not $10 \mathrm{ppm}$ ) naphthalene by female B6C3F1 mice; relatively high mortality in control male mice in this study made results in that sex more difficult to evaluate (NTP, 1992, 2002; Abdo et al., 1992). Histopathology findings from this study are consistent with DMOA carcinogenesis, particularly in view of related cytotoxicity information from other studies. Chronic naphthalene exposures at these levels produced dose-dependent cytotoxicity in the same (distal-bronchial/alveolar) lung region in mice, but not in rats (West et al., 2001). Relative to neighboring cells, non-ciliated Clara cells exhibited particularly high susceptibility to naphthalene-induced cytotoxicity. These cells also demonstrate the greatest capacity to metabolize naphthalene, as discussed below. General, granulomatous and glandular inflammation and alveolar epithelial hyperplasia were all significantly elevated among the highdose female mice. "Alveolar epithelial hyperplasia occurred primarily in or adjacent to areas of inflammation" (Abdo et al., 1992). In earlier studies, a single 125- or 250-mg/kg ip injection of naphthalene was sufficient to cause bronchial and bronchiolar epithelial necrosis in mice (Mahvi et al., 1977, Tong et al., 1981). Mild to moderate nasal respiratory epithelial hyperplasia also occurred in $100 \%$ of all dosed female and in $>95 \%$ of all dosed male mice, but in virtually none of the control mice.

Histopathology findings obtained from the NTP (2000) rat bioassay provide clear evidence that nasal tumor formation in rats chronically exposed to naphthalene by inhalation was at least substantially influenced, if not driven primarily, by chronic tissue damage and associated 
regenerative and focal hyperplasia. The extent of chronic nasal cytotoxicity and hyperplasia detected in nearly $100 \%$ of all exposed animals (regardless of dose group) was described by Long et al. (2003) as follows (bold added):

\begin{abstract}
"Neuroblastomas occurred amid a complex spectrum of nonneoplastic lesions of the olfactory epithelium. The principal nonneoplastic proliferative lesion was atypical hyperplasia, which ... consisted of proliferating nests of dysplastic olfactory epithelial cells ... and/or multifocal nodular proliferations of basal cells extending into the submucosa .... The hyperplastic cells were deeply basophilic and, in many areas, continuous with the neoplasms. Such continuity was most clearly observed in association with small neuroblastomas. Atrophy of olfactory epithelium was characterized by ... loss of epithelial cells ... there was also loss of olfactory neurons. The most severe lesions had complete loss of sustentacular cells and neurons, leaving only basal epithelial cells.
\end{abstract}

Respiratory epithelial adenomas also occurred amid a spectrum of non-neoplastic lesions of the respiratory epithelium and the submucosal glandular epithelium.... In a few animals, focal proliferation of hyperplastic cuboidal respiratory epithelium resembled early adenoma formation.

... Although the incidence and severity of these non-neoplastic lesions frequently increase in an exposure-dependent manner, they commonly occur with no evidence of nasal carcinogenicity, indicating that factors other than the extent of tissue injury from chronic nasal toxicity contribute to nasal carcinogenesis ... . Atypical hyperplasia of the olfactory basal cells occurred at very high frequencies in all male and female groups exposed to naphthalene. This was considered an unusual proliferative lesion, because it had not been reported in previous NTP inhalation studies. Morphologically, these cells were similar to, and frequently formed a continuum with, those of the neuroblastomas. This appearance suggests that the atypical hyperplasia may represent a precursor for nasal olfactory carcinogenesis. In addition, a few animals had localized proliferative changes of the respiratory epithelium that were morphologically similar to respiratory epithelial adenomas."

This description of cytotoxicity and hyperplasia, in direct association with the observed nasal neuroblastomas and nasal respiratory epithelial adenomas, is similar to descriptions of multistep neoplastic transformation from focal hyperplastic tissue to nodular hyperplasia to adenomas or carcinomas observed in chemically induced or promoted carcinogenesis in the rodent liver and gastrointestinal tract (Farber, 1984; Farber and Cameron, 1984; Pitot et al., 2000). While initiation with a genotoxic agent is typically used in these experimental rodent carcinogenesis systems in order to generate observable tumor rates, subsequent promotion involving either enhanced cell proliferation, or just oxidative stress associated with additional genotoxic or cytotoxic exposure(s) (Sanchez-Perez et al., 2005), can be required to elevate these rates to observable levels.

Naphthalene was clearly cytotoxic to epithelial and neural cells in nasal tissue of exposed NTP (2000) bioassay rats. The observed cytotoxic damage and histologically linked 
regenerative hyperplasia strongly support the hypothesis that these effects likely amplified the incidence of tumor occurrence in that study, through clonal expansion of premalignant cell populations that then became available for subsequent malignant transformation (Moolgavkar, 1983; Bogen, 1989). As further discussed below, a site-specific genotoxic MOA appears also to have been involved, as may be indicated by absence of nasal tumors in similarly exposed mice, despite evidence of (somewhat less severe) nasal epithelial hyperplasia and tissue damage (NTP, 1992; Abdo et al., 1992). Because a cytotoxic MOA contributed to those tumors to an unknown but clearly nonzero extent, fundamental MOA uncertainty is intrinsic to any estimate of low-dose cancer risk associated potential genotoxicity that may also have contributed to rat nasal tumor formation in the NTP (2000) bioassay. However, the fact that such fundamental MOA uncertainty exists does not negate the histological evidence, referred to above, that clearly link regenerative hyperplasia to adjacent, surrounding and/or nearby neoplasia in naphthalene-exposed rats.

\subsection{Naphthalene Metabolite Cytotoxicity}

Naphthalene is metabolically activated by one or more forms of cytochrome P450 (CYP) to a chiral 1,2-epoxide, which can react directly to form covalent adducts with cellular nucleophiles such as DNA and protein, or undergo subsequent transformation to other reactive metabolites (including 1,2- and 1-4-naphthoquinones) or to detoxified intermediates that are excreted, primarily in urine (Buckpitt and Franklin, 1989; Buckpitt et al., 2002; Waidyanatha et al., 2002; EPA, 2004; ATSDR, 2005). CYP-mediated metabolic bioactivation of naphthalene varies considerably among species and among different anatomical regions of the respiratory tract; it correlates with observed region-, organ- and species-specific susceptibility to naphthalene-induced cytotoxicity and carcinogenicity (O’Brien et al., 1985; Buckpitt and Bahnson, 1986; Buckpitt et al., 1992, 1995, 2002; Thornton-Manning and Dahl, 1997; Baldwin et al., 2004, 2005; Boland et al., 2004).

Glutathioine-S-transferase (GST) activity is a key barrier to cytotoxicity associated with reactive naphthalene metabolites, and glutathione depletion before naphthalene exposure enhances acute naphthalene-induced injury in mouse-lung Clara cells, which are observed to be early and relatively susceptible targets of cell killing that occurs at all concentrations associated with naphthalene-related lung tumorigenesis (Warren et al., 1982; West et al., 2000; Plopper et 
al., 2001; Phimester et al., 2004, 2005). Greater susceptibility of cells in terminal/distal vs. upper lung regions to naphthalene-induced cytotoxicity in mice, or to ozone-induced cytotoxicity in monkeys, is not explained by regional differences in rates of glutathione resynthesis (Duan et al., 1996). In isolated murine Clara cells, decreased cell viability was non-detectable at naphthalene is substantial ( $\geq 63 \%$ ) at naphthalene concentrations $\geq 0.5 \mathrm{mM}$, but is blocked by preincubation with the CYP inhibitor, piperonyl butoxide (Chichester et al., 1993). In those isolated cells, incubation with a $0.5-\mathrm{mM}$ concentration of naphthalene, its dihydrodiol, 1-naphthol, or 1,2naphthoquinone all decrease cell viability to about the same degree; however, this concentration of naphthalene oxide or 1,4-naphthoquinone causes even greater cytotoxicity, unblocked by piperonyl butoxide (Chichester et al., 1993). In isolated mouse-lung Clara cells exposed to naphthalene, 1,2-naphthoquinone was one of two detected types of covalent, naphthalene-related protein adduct (Zheng et al., 1997). Glutathione depletion alone appears not to explain the necrotic response of murine Clara cells to naphthalene; rather, ultrastructural studies indicate that this cytotoxic response appears to require mitochondrial damage induced by reactive naphthalene metabolites (Phimester et al., 2005). Inhaled (but not ip-administered) naphthalene induces dosedependent Clara cell cytotoxicity in mice, whereas the same cell type does not exhibit this sensitivity in rats (West et al., 2001).

Necrosis of bronchial epithelial (Clara) cells in mice (Tong et al., 1981; Buckpitt and Warren, 1983; O’Brien et al., 1985, 1989) and necrosis of olfactory epithelial cells in mice, rats and hamsters (Plopper et al., 1992) following intraperitoneal injection of naphthalene strongly indicate that metabolic activation in target tissues plays a dominant, and possibly exclusive, role in site-specific naphthalene cytotoxicity. There is no evidence that unmetabolized naphthalene is cytotoxic.

Human liver microsomes convert naphthalene to its dihydrodiol intermediate at faster rates than mouse and rat liver microsomes (Kitteringham et al., 1996). The human enzyme that is orthologous to the mouse CYP2F2 enzyme is CYP2F1. The CYP2F1 mRNA has been identified in human respiratory tissues by a number of different laboratories (see Raunio et al., 1999; Ding and Kaminsky, 2003). The CYP2F1 enzyme is expressed in lymphoblastoid cells where it metabolizes naphthalene to its epoxide, albeit at very low rates (Lanza et al., 1999). Immunolocalization failed to detect $\mathrm{CYP} 2 \mathrm{~F}$ in rhesus macaque tissue of any kind studied other 
than nasal ethmoturbinates, where levels were 10- and 20-fold lower than in corresponding rat and mouse tissue, respectively (Baldwin et al., 2004). Pooled human liver microsomes (pHLMs) can metabolize naphthalene to trans-1,2-dihydro-1,2-naphthalenediol (dihydrodiol), 1-naphthol and 2-naphthol; further pHLM metabolism of 2-naphthol produces 2,6- and 1,7dihydroxynaphthalene, whereas dihydrodiol and 1-naphthol are not efficiently metabolized by pHLMs (Cho et al., 2006).

\subsection{Correlation of Genotoxicity and Cytotoxicity Induced by Naphthalene Metabolites}

Prokaryotic and eukaryotic in vitro study results indicate that without metabolic activation, naphthalene itself does not damage DNA (Schreiner, 2003). In contrast to the parent compound, naphthalene metabolites, such as 1,2- and 1,4-naphthoquinone, were found to be positive for genotoxicity in a relatively small subset of prokaryotic and eukaryotic in vitro studies involving metabolic activation (Arfsten et al., 1994; Flowers-Geary et al., 1996; NTP, 1992; Wilson et al., 1995, 1996; Sasaki et al., 1997; Yu et al. 2002; Schreiner, 2003). The clearest evidence for this involved human lymphoid cells exposed to 1,2- and/or 1,4-naphthoquinone. After 2 hours of exposure to $0.1 \mu \mathrm{g} / \mathrm{mL}(0.63 \mu \mathrm{M})$ 1,4-naphthoquinone, MCL-5 human B-lymphocytes (which express several transfected CYP and epoxide hydrolase genes) exhibited a significant ( 2-fold) increased frequency of micronuclei, but not of mutation frequency at the $\mathrm{TK}^{-}$or the HPRT ${ }^{-}$locus assayed (Sasaki et al., 1997). The mutation assay performed was associated with substantially decreased $(66 \pm 20 \%)$ cell survival, but not the micronuclei assay. Human mononuclear lymphocytes (MNL) exposed to various concentrations of naphthalene, 1,2-epoxynaphthalene, 1napthol, 1,2- naphthoquinone or 1,4-naphthoquinone were assayed for glutathione (GSH) depletion, for cytotoxicity and for sister chromatid exchange (SCE) frequency by Wilson et al. (1996). Exposure for 2 hours to the 1-napthol metabolites, 1,2- naphthoquinone or 1,4naphthoquinone, were observed to be directly toxic to MNL and to deplete GSH to up to $1 \%$ of control levels (Wilson et al., 1996). Cytotoxicity data from this study, replotted in Figure 1, indicate that cell killing by both of these naphthalene metabolites is modeled reasonably well as a linear function of $\log$ concentration. Note that the relationship shown in Figure 1 predicts the average amount of cell killing observed for cells exposed to $0.1 \mu \mathrm{g} / \mathrm{mL}=0.63 \mu \mathrm{M} 1,4-$ naphthoquinone, by Sasaki et al., 1997. 


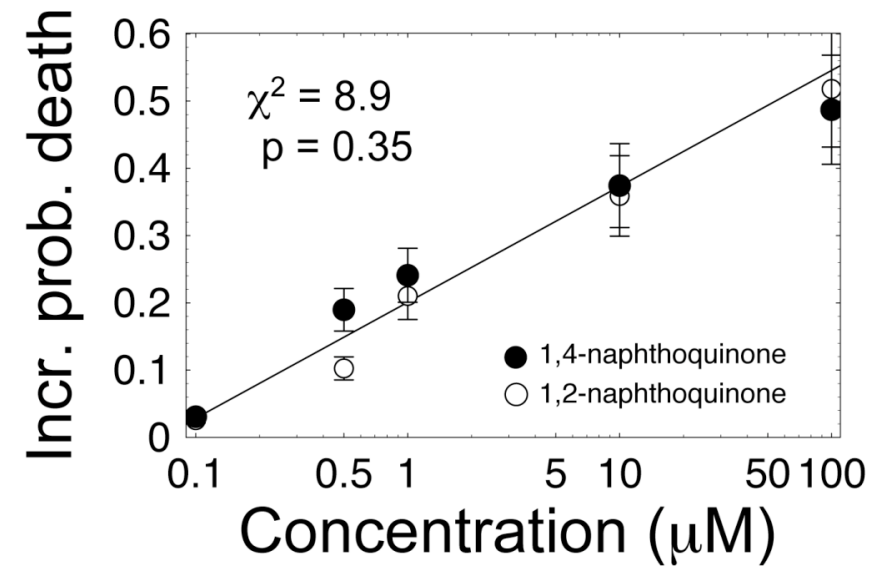

Figure 1. Increased fraction $F(c)$ of MNL killed by a 2-hour exposure to different concentrations $c$ of either 1,2- or 1,4naphthoquinone, based on data reported by Wilson et al. (1996), modeled as $F(c)=[P(c)$ $-P(0)] /[1-P(0)]=0.201( \pm 0.011)+0.0749$ $( \pm 0.0051) \log (c)$, where $P(0) \approx 2.5 \%$, and parameter estimates $( \pm 1 \mathrm{SE})$ were obtained by iteratively reweighted least-squares linear regression (Carrol and Ruppert, 1988), assuming measurement errors equal approximately one sixth of each reported measure (indicated by plotted error bars). Goodness of fit statistics are shown.

SCE frequencies reported in Figure 5 of Wilson et al. (1996) for similarly exposed MNL cells relative to control cells is likewise well modeled (by unweighted linear regression) as the following linear function of log concentration: Fold-increase in SCE/chromosome $=1.006( \pm$ $0.038)+0.055( \pm 0.0013) \log (c)\left(\mathrm{R}^{2}=0.998, \mathrm{p}=0.018\right.$ for a zero-slope null hypothesis $)$, based on SCE data obtained for each naphthoquinone at 1, 10 and $100 \mu \mathrm{M}$ concentrations. Combining this relationship with that shown in Figure 1 above (with Y-intercept assumed to be unity) yields an estimated relation between relative risk $(\mathrm{RR})$ of $\mathrm{MNL}$ cell death, modeled as $\mathrm{RR}=1 /[1-F(c)]$, and corresponding RR for SCE-equivalent DNA damage or mutation, shown in Figure 2. This relationship implies that any substantial increase in the background rate of critical DNA damage from the most potent of genotoxic metabolites that may arise from exposure to naphthalene is

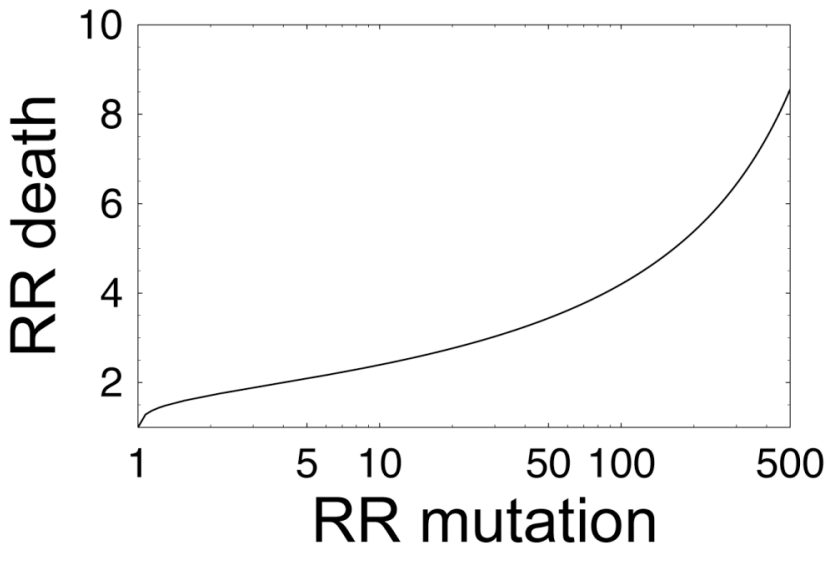

Figure 2. Relative risk (RR) of cell death as a function of RR of SCE-equivalent DNA damage or mutation, inferred from cytotoxicity and SCE data gathered by Wilson et al. (1996) on MNL cells exposed to naphthoquinones. The modeled relationship is $\mathrm{RR}_{\text {death }}=\operatorname{Max}(1,1 /[0.5280-$ $\left.\left.\log \left(\mathrm{RR}_{\mathrm{mut}}-1\right) / 13.358\right]\right)$. 
predicted to be accompanied invariably by substantially increased likelihood of cell death due to cytotoxicity. Notably, naphthalene 1,2-epoxide ( 2 hours at 1 to $100 \mu \mathrm{M}$ ) was found in the same study to cause neither GSH depletion, cytotoxicity, nor SCE induction (Wilson et al., 1996). Cytotoxicity was observed in MNL exposed for 2 hours to 10 or $100 \mu \mathrm{M}$ concentrations of either naphthalene and 1-naphthol in the presence of rat liver microsomes, but the response to 1naphthol (approaching that due to equal concentrations of 1,2- or 1,4-naphthoquinone) far exceeded that to naphthalene (Wilson et al., 1996).

The pattern shown in Figure 2 exhibits a strong, positive, non-threshold association similar that observed between genotoxicity and cytotoxicity exhibited by other classes of mutagenic, carcinogenic and antineoplastic agents, such as chemical alkylating agents (Sanderson et al., 1991) and ionizing radiation (Stewart, 2001). Data used to derive Figure 2 were selected (conservatively) to represent the combination of available data reflecting the greatest genotoxic potency with plausibly linear low-dose dose-response, combined with the least associated cytotoxicity (i.e., reflecting the smallest plausible ratio $\rho=\mathrm{RR}_{\text {death }} / \mathrm{RR}_{\mathrm{mut}}$ of cytotoxic to mutagenic potency), that was likely to have occurred when bioassay rats were dosed with naphthalene. The value of $\rho$ may be concentration-dependent, as reflected in the nonlinear relation shown in Figure 2, and perhaps also tissue-dependent. The value of $\rho$ varies directly with the magnitude $S$ of risk overestimation that occurs under a genotoxic MOA assumption when a DMOA is true involving cytotoxicity-driven hyperplasia, as predicted by a 2-stage MVK-type cancer-risk model of the type applied later (Section 3). For example, $\rho=0$ and $S=1$ (indicating no such overestimation) for any carcinogen with a purely genotoxic MOA. To conservatively estimate the value of $S$ via the method proposed in Section 3, the smallest value of $\rho$ should be used that is plausibly consistent with relevant available data. In the context of observed naphthalene-induced tumors in rats and mice, given available cytotoxicity and genotoxicity data discussed above, it is proposed that the function plotted in Figure 2 reflects a lower plausible bound on the value of $\rho$ as a function of $\mathrm{RR}_{\text {mut }}$, where SCEs are used here as a surrogate measure of maximum plausible mutagenic effect.

\subsection{PBPK-Based Prediction of Site- and Species-Specific Naphthalene Cytotoxicity}

Physiologically based pharmacokinetic (PBPK) models developed for naphthalene (Sweeney et al., 1996), and for naphthalene and its 1,2-epoxide metabolite and associated 
reaction products (Quick and Shuler, 1999; Ghanem and Shuler, 2000; Willems et al., 2001), have been used to describe and explore plausible measures of biologically effective dose pertaining to naphthalene toxicity and carcinogenicity. PBPK model parameters governing naphthalene metabolism for the earlier models were estimated entirely from in vitro metabolic data, and then were compared and/or partially optimized to previously published data on levels of naphthalene in blood, tissue-specific $\mathrm{GSH}$, and ${ }^{14} \mathrm{C}$-radiolabeled adducts covalently bound to tissue-specific macromolecules in mice and rats exposed in vivo to naphthalene by intravenous (iv) injection, intraperitoneal (ip) injection, or oral dosing (Sweeney et al., 1996; Quick and Shuler, 1999; Ghanem and Shuler, 2000). The Quick and Shuler (1999) model, summarized in Figure 3, predicts detailed, time-dependent patterns of covalent binding and GSH depletion in lung and in liver of mice administered naphthalene by ip injection that were shown to be reasonably consistent with a range of previously published data, including detailed data reported by Warren et al. (1982) for mice ip-injected with radiolabeled naphthalene.

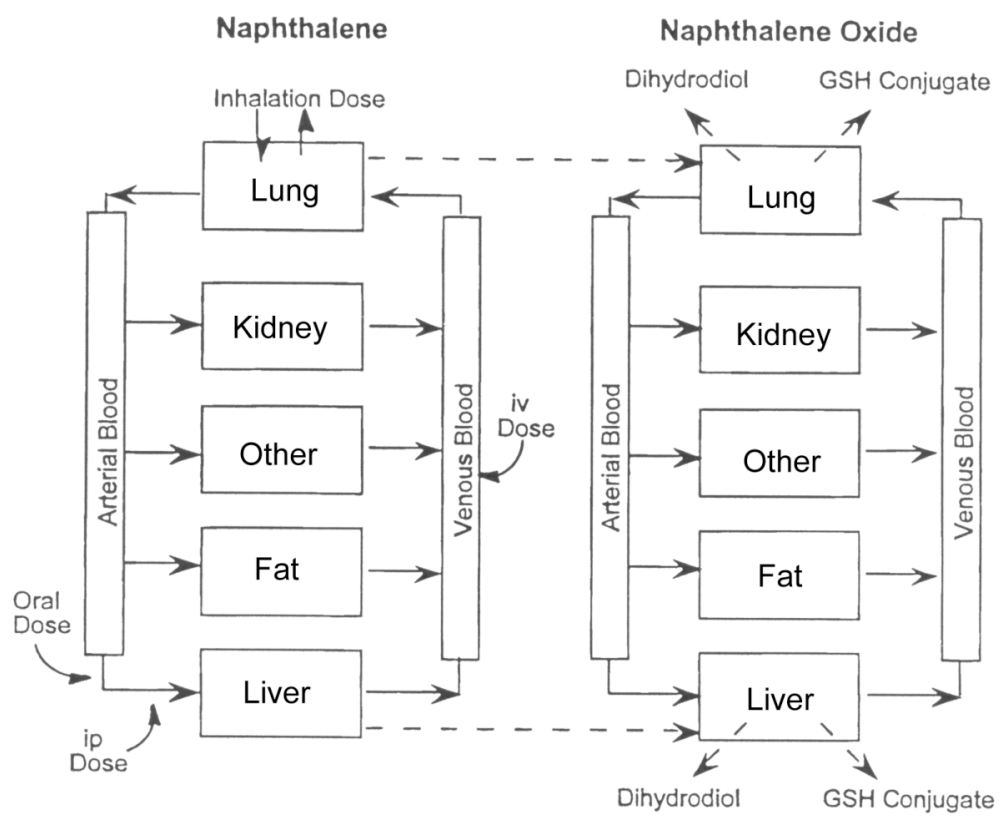

Figure 3. The flow-limited PBPK model of Quick and Shuler (1999) describing uptake, distribution and metabolism of naphthalene. Arrows denote flows, dashed arrows CYP-mediated metabolic transformation (Kidney and Other compartments were referred to as Richly and Poorly Perfused compartments, respectively). In the related Willems et al. (2001) model, each naphthalene compartment is split into two corresponding diffusion-limited subcompartments: one each for the tissue and its capillary bed.

The Willems et al. (2001) model modified the Quick and Shuler (1999) model in two ways. First, all naphthalene-specific model compartments were restructured to reflect a "distributed blood" assumption that intra-compartment naphthalene distribution is limited by 
diffusion rather than by blood flow (i.e., perfusion). The "distributed blood" framework was developed by Kohn (1997), who showed this approach to provide a more realistic model the kinetics of respiratory 1,3-butadiene uptake by mice. Second, Willems et al. (2001) replaced the submodel for glutathione (GSH) turnover used by Quick and Shuler (1999) with the generic GSH model incorporated into the PBPK model otherwise developed specifically for 1,3butadiene (Kohn and Melnick, 2000). Using this modified PBPK model, Willems et al. (2001) estimated parameters governing CYP-mediated naphthalene metabolism in both liver and lung by fitting model predictions for naphthalene in chamber air in rats exposed for 6 hours (once, or daily for two weeks) to concentrations of 10, 30 or $60 \mathrm{ppm}$ naphthalene, and for naphthalene in blood of mice exposed for 6 hours (once, or daily for two weeks) to concentrations of 10, 30 or $60 \mathrm{ppm}$ naphthalene-i.e., using respiratory exposure protocols similar to those used in the NTP (1992, 2000) rodent bioassays that indicated positive carcinogenicity.

Section 2.4.1 describes predictions made by the Willems et al. (2001) model, and in particular how certain of these predictions involving tissue-specific GSH levels deviate substantially from corresponding experimental observations. Section 2.4.2 describes a modification of the Willems et al. (2001) PBPK model that predicts tissue-specific GSH levels more consistent with experimental observations.

\subsubsection{Willems et al. (2001) PBPK Model}

Willems et al. (2001) showed that their model fairly accurately predicted their newly obtained in vivo data on naphthalene uptake and distribution in rats and mice. This model also predicted patterns of tissue-specific GSH depletion that appear to provide some insight into why lung might be much more susceptible to naphthalene-induced cytotoxicity than liver. Figure 4 shows tissue-specific relative GSH concentrations predicted by the Willems et al. (2001) model in $0.5-\mathrm{kg}$ male rats exposed for 6 hours to $10 \mathrm{ppm}$ naphthalene by inhalation. This model consists of the system of linear and nonlinear ordinary differential equations and parameter definitions defined by Willems et al. (2001) and papers cited therein, here implemented using Mathematica $5.0^{\circledR}$ software (Wolfram, 1999).

Figure 4 (left panel) shows the Willems et al. (2001) model to predict rapid GSH depletion in lung, but not in liver-very similar to (but with greater detail over a 6-hour period than) predictions summarized for similarly exposed ( $\sim 0.14-\mathrm{kg}$ female) rats in the upper left and 

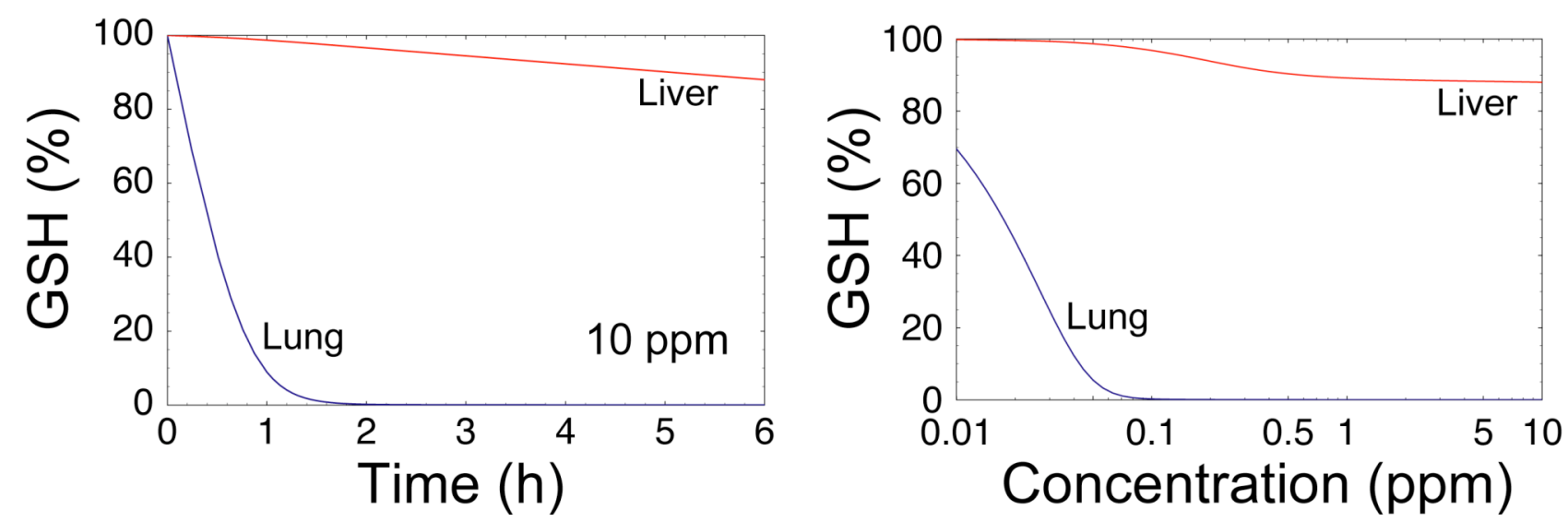

Figure 4. Glutathione (GSH) concentrations predicted by the PBPK model of Willems et al. (1999) for rats exposed to naphthalene in air, relative to those in non-exposed animals, in liver (red curve) and lung (blue curve). (Left) GSH levels predicted in rats exposed to $10 \mathrm{ppm}$ naphthalene as functions of time; (right) GSH levels after $6 \mathrm{~h}$ of respiratory exposure as a function of naphthalene air concentration.

right panels of the "Figure 5" that appears in the study by Willems et al. (2001). That figure from that study showed results corresponding to a 5 day/week pattern of 6-hour respiratory exposures over a 3-week period (in contrast to the 6-hour time frame shown in Figure 4), demonstrating that repeated previous exposures have very little effect on tissue-specific levels of GSH depletion predicted after 6 hours of respiratory exposure to naphthalene.

Species- and site-specific predictions of cytotoxicity based on PBPK modeling can provide a mechanistic, experimentally testable basis for toxicokinetic models applicable to cancer risk extrapolation. In view of data indicating the critical role of GSH depletion in cytotoxicity that can be induced by naphthalene or its metabolites discussed earlier, PBPK-model predictions of species-, sex- and site-specific differences in such GSH-depletion offer critical mechanistic insight into the potential role that cytotoxicity may have played in dose-response observed in naphthalene cancer bioassays. However, a prerequisite for such interpretation is PBPK model validation that includes reasonable agreement with a range of relevant experimental observations. In this regard, GSH predictions like those shown in Figure 4 are questionable in view of the fact that analogous predictions made by the Willems et al. (2001) model for mice exposed to $200 \mathrm{mg} / \mathrm{kg}$ naphthalene by ip injection (Figure 5) deviate markedly from relative GSH measures reported by Warren et al. (1982) (reprinted in Figure 6, below). In particular, note the substantially different appearance between predicted tissue-specific temporal patterns of 

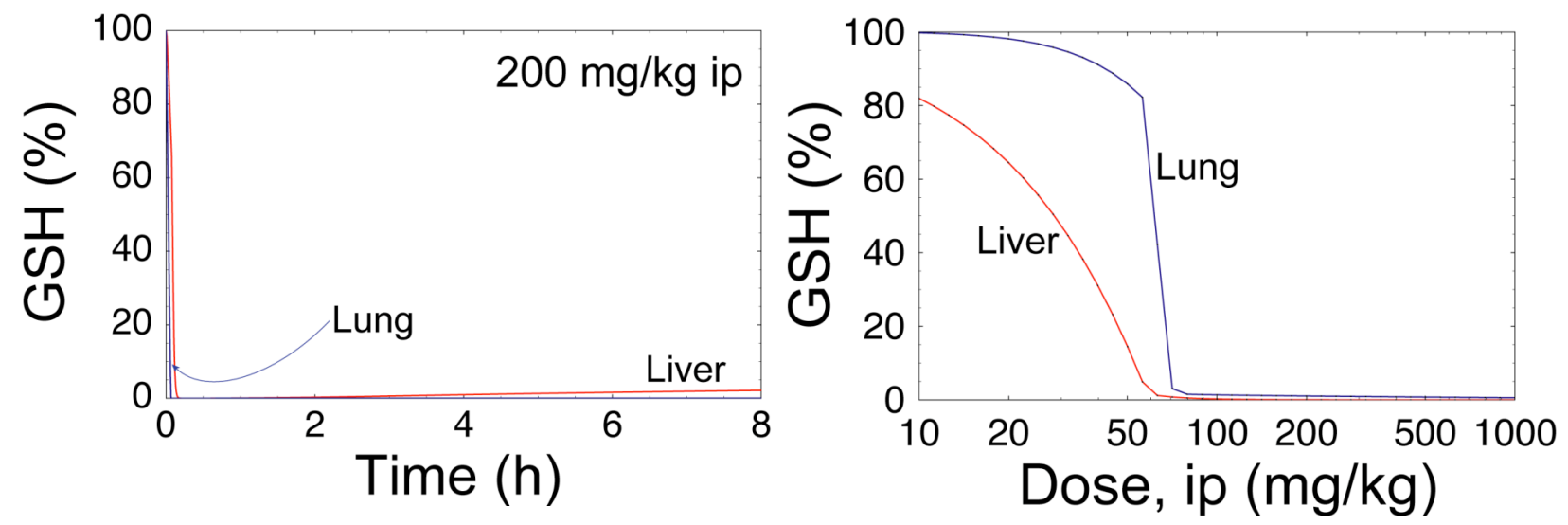

Figure 5. Glutathione (GSH) concentrations predicted by the PBPK model of Willems et al. (1999) for mice ip-injected with naphthalene, relative to that in non-exposed animals, in liver (red curve) and lung (blue curve). (Left) GSH levels predicted in mice ip-injected with $200 \mathrm{mg} / \mathrm{kg}$ naphthalene as functions of post-injection time; (right) GSH levels $4 \mathrm{~h}$ after ip injection as functions of naphthalene dose.

GSH level shown in Figure 5 (left) vs. corresponding data shown in Figure 6 (panels a and c), and likewise between predicted tissue-specific patterns of GSH level as functions of dose shown in Figure 5 (right) vs. corresponding data shown in Figure 6 (panels e and g).

Although, as noted above, experimental data reported by Warren et al. (1982) were modeled fairly well by the flow-limited PBPK model of Quick and Schuler (1999), the parameters governing CYP-mediated naphthalene metabolism used in that model were estimated directly from in vitro rather than in vivo data, and it moreover relied on potentially unrealistic submodel structures for GSH-turnover and for tissue-specific naphthalene partitioning. These issues were all addressed in the model of Willems et al. (2001), but this presumably more realistic model evidently fails to predict key empirical data that were predicted fairly well by the Quick and Schuler (1999) model. It is not clear whether or to what extent Willems et al. (2001) intended their PBPK model to agree with specific sets of previously published experimental data concerning naphthalene metabolites or GSH depletion, rather than to provide an initial basis for model development and exploration, since that study included only comparisons between predictions made by their model and corresponding sets of in vivo data they reported for chamber-air or blood concentrations of naphthalene in mice or rats exposed to naphthalene by inhalation or by iv injection. 

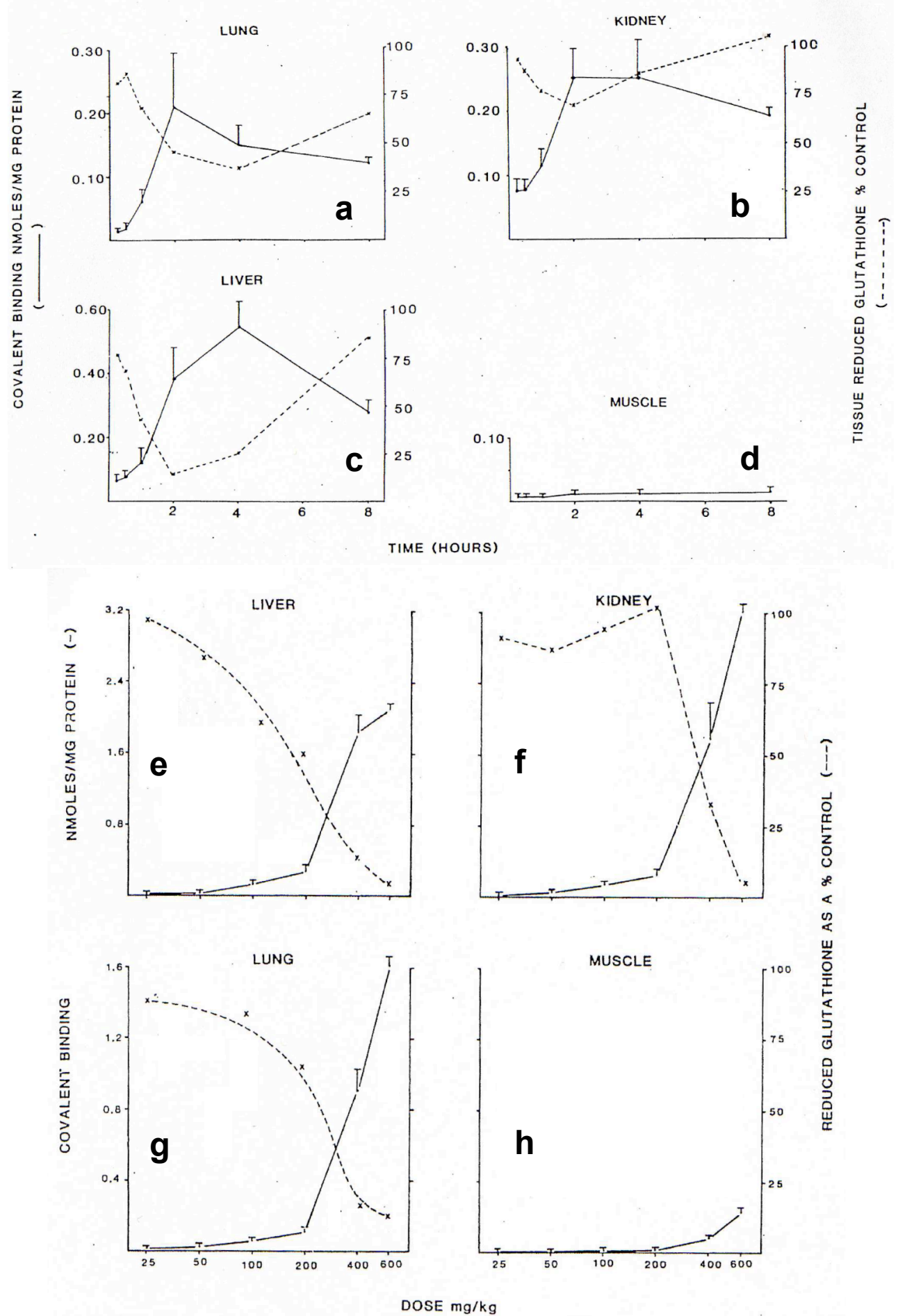

Figure 6. Tissue-specific levels of covalent binding (left axes) and relative glutathione (GSH) depletion (right axes) reported by Warren et al. (1982; in Figures 2 and 3 from that study) and by Buckpitt and Warren (1983) for 20- to 25-g male Swiss Webster mice ip-injected with ${ }^{14} \mathrm{C}$-radiolabeled naphthalene. (Panels a-d) levels predicted in mice ip-injected with $200 \mathrm{mg} / \mathrm{kg}$ naphthalene as functions of postinjection time; (panels e-h) levels $4 \mathrm{~h}$ after ip injection as functions of naphthalene dose. Note the substantially nonlinear, upward bend in dose-response covalent binding, and associated GSH depletion $\geq 50 \%$, observed to occur in all tissues at doses $\geq \sim 200 \mathrm{mg} / \mathrm{kg}$ (panels e-h). This "hockey-stick" doseresponse pattern is consistent with dose-related saturation of GSH-mediated deactivation of reactive naphthalene metabolites. 


\subsubsection{Willems-Quick-Scheuler-Modified (WQSM) PBPK Model}

To address discrepancies associated with the Willems et al. (2001) model discussed in Section 2.4.1, this model was for the purpose of the present analysis modified in the following four ways, which are further described below: (1) different values are used for certain GSHrelated parameters, (2) kidney was added to (liver and lung) compartments in which GSH conjugation to naphthalene oxide is presumed to occur mediated by glutathione-S-transferase (GST) activity, (3) a different structure of the GSH-turnover submodel is used, and (4) a different assumption was used concerning the uptake of naphthalene administered by ip injection. Below, this modified PBPK model is referred to as the Willems-Quick-ScheulerModified (WQSM) model, which differs from that of Willems et al. (2001) as described below.

The WQSM model is otherwise identical in all respects to all aspects of the Willems et al. (2001) "distributed blood" model that pertains directly to naphthalene uptake, distribution and metabolism (i.e., the part of their overall model summarized by "Naphthalene" components shown on the left side of Figure 3 above).

(1) GSH-related parameters. For the WQSM model, values of selected GSH submodel parameters were changed to correspond to those measured in 20- to 25-g male Swiss-Webster mice exposed by Warren et al. (1982) to naphthalene by ip injection. Specifically, the values 1800 and $7500 \mu \mathrm{M}$ listed by Quick and Shuler (1999), and used by Willems et al. (2001), for the parameter $\left(C_{x}^{\mathrm{GSHss}}\right)$ specifying steady-state GSH concentration in mouse tissue $x$ for $x=$ lung and liver, respectively, were replaced by 706, 2434 and $1420 \mu \mathrm{M}$ for $x=1$ lung, liver and kidney, respectively, which are the corresponding reported mean values of measures made by Warren et al. (1982). The values 2750 and $280 \mu \mathrm{M} / \mathrm{min}$ listed by Quick and Shuler (1999), and used by Willems et al. (2001), for the parameter $\left(V_{\mathrm{max}, x}^{\mathrm{GST}}\right)$ specifying the maximal rate of GST-mediated GSH conjugation to naphthalene oxide in the mouse tissues $x=$ lung and liver, respectively, were replaced by 200, 1000 and $200 \mu \mathrm{M} / \mathrm{min}$ for $x=$ lung, liver and kidney, respectively, determined by qualitative optimization of WQSM model predictions to tissue-specific GSH data of Warren et al. (1982). Likewise, the values 26.4, 102 and $75.6 \mathrm{nmol} / \mathrm{mg} / \mathrm{hr}$ cited by Kohn and Melnick (2000), and used by Willems et al. (2001), for the parameter ( $\left.V_{\max , x}^{\mathrm{GGS}}\right)$ specifying the maximal rate of GSH synthesis by $\gamma$-glutamyl synthetase (GGS) in the mouse tissues $x=$ lung and liver, 
respectively, were replaced by 80,85 and $30 \mathrm{nmol} / \mathrm{mg} / \mathrm{hr}$ for $x=$ lung, liver and kidney, respectively.

Parameter values used for rats were unchanged, except that the values 1800 and $7500 \mu \mathrm{M}$ listed by Quick and Shuler (1999), and used by Willems et al. (2001), for the parameter ( $C_{x}^{\mathrm{GSHss}}$ ) specifying steady-state GSH concentration in rat lung and liver, respectively, were replaced by 2500, 10000 and $2000 \mu \mathrm{M}$ for $x=$ lung, liver and kidney, respectively, based on corresponding daytime measures in male Sprague-Dawley rats reported by Farooqui and Ahmed (1984).

(2) Kidney metabolism. While all active mammalian cells use GSH to bind oxidative products of mitochondrial and cytosolic metabolism, key metabolizing tissues (including liver, kidney, lung and intestine) synthesize and maintain comparatively high GSH concentrations, with liver being a primary source of GSH exported in systemically circulating blood (in which $98 \%$ of the GSH is contained in red blood cells), from which GSH is transported to and extracted by other organs - principally in the kidney - as a primary source of cysteine used for (e.g., GGSmediated) intracellular GSH resynthesis (Dass et al., 1992; Lohr, 1998; Lash, 2005). The kidney is among mammalian tissue types that express the greatest levels of GST-specific mRNA, reflecting relatively high GSH turnover in these tissues as one of the key mechanisms cells use to effectively inhibit oxidative stress that may arise from a variety of normal and pathological processes (Estonius et al., 1999; Forsberg et al., 2001). A PBPK model of naphthalene oxide (NO) that omits its elimination via GSH-conjugation in kidney is thus unlikely to be realistic, particularly in view of covalent binding and GSH depletion in kidney tissue of mice (but not rats) exposed to a sufficiently high dose of naphthalene (see, e.g., Warren et al., 1982; Buckpitt and Warren, 1983; O’Brien et al., 1985).

(3) GSH-turnover submodel. For the WQSM model, NO elimination via GSHconjugation in kidney was reflected by subtracting from the expression used to model the rate $d \mathrm{NO}_{x}(t) d t$ (the time derivative of NO concentration in tissue $x$, with $x=$ kidney), the same form of $x$-specific ("ping-pong" saturation kinetics) term as those used by Quick and Shuler (1999) and Willems et al. (2001) to denote rates of GGS-mediated NO-loss in expressions representing $d \mathrm{NO}_{x}(t) d t$ for liver and lung. This term also appears in tissue-specific GSH-turnover submodels used by Willems et al. (2001), based on the generic model described by Kohn and Melnick (2000), where this term was denoted $v_{\text {synthesis }}^{\mathrm{GSH}, x}$, except that specificity to tissue $x$ appears explicitly in the latter notation. Likewise, $x$-specific expressions for the rates $d \mathrm{GSH}_{x}(t) d t$ and $d \mathrm{Cys}_{x}(t) d t$ of 
change in concentration of GSH and its cysteine precursor, respectively, contained in tissue $x$ was added for $x=$ kidney, using forms identical to those used for lung and liver tissues by Quick and Shuler (1999) and Willems et al. (2001), except that in the WQSM model, each calculated rate constant for cysteine uptake (denoted $v_{\text {up }}^{\text {Cys, } x}$ used in the GSH-turnover model of Kohn and Melnick, 2000) was multiplied by a corresponding term $S_{x}(t)$ assumed to be proportional in the following way to the ratio $R_{x}(t)=C_{x}^{\mathrm{GSHss}} / \mathrm{GSH}_{x}(t)$ (i.e., to the magnitude of tissue-specific GSH depletion at time $t$ ):

$$
S_{x}(t)=\operatorname{Min}\left(W_{x}\left[R_{x}(t)\right]^{n_{x}}, b\right),
$$

where exponents $n_{x}$ were assumed to be fixed at values of 1.5, 1.5 and 8 for $x=$ lung, liver and kidney, respectively; and $W_{x}=1$ with upper bound $b=5$ were assumed for $x=$ lung and liver. The $S_{x}(t)$ term represents an assumption that active-transport-mediated uptake of extracellular cysteine actively responds to GSH depletion by increasing above its initial value $v_{\mathrm{up}}^{\mathrm{Cys}, x}$ to a rate proportional to a power of $R_{x}(t)$ but $\leq b v_{\mathrm{up}}^{\mathrm{Cys}, x}$. Finally, only for $x=$ kidney, the $\left(1+\mathrm{GSH}_{x}(t) / K_{i}\right)$ term used in the GSH-metabolism model of Kohn and Melnick (2000) was replaced by the more responsive "ping-pong" saturation term, $\left[\mathrm{GSH}_{x}(t) / C_{x}^{\mathrm{GSHss}}\right]^{2}$.

Using $W_{\text {kidney }}=1$, this revised GSH-turnover model was found to be unable to fit the empirical kidney GHS data obtained by Warren et al. (1982), predicting only a gradual decline, instead of the observed sharp decline, in mouse kidney GSH at ip naphthalene doses $>200 \mathrm{mg} / \mathrm{kg}$. The observed sharp decline near that dose would, however, be explained if GSH in circulating blood - which is continuously extracted as a cysteine source by the kidney (Dass et al., 1992; Lash, 2005) — were proportional to GSH in liver, such that whenever GSH in liver (and consequently, in blood) becomes depleted below a critical threshold fraction $f$, cysteine extraction by the kidney becomes sharply reduced. In the WQSM model, this assumption is reflected for $x=$ kidney by setting $W_{x}=5\left[R_{x}(t) / f\right]^{-n_{x}}$ for all $\left[R_{x}(t)\right]^{-1}<f$, and $W_{x}=1$ otherwise, with $f=40 \%$.

(4) Uptake of naphthalene administered by ip injection. Finally, Quick and Schuler (1999) assumed that ip-injected naphthalene is absorbed entirely by the liver within one minute. The WQSM model assumes instead that only a fraction $f_{\text {liv }}$ of ip-injected naphthalene is absorbed 
directly into liver tissue with an absorption half-time of $150 \mathrm{~min}$, while the remaining fraction $\left(1-f_{\text {liv }}\right)$ is absorbed entirely into the "Other" (slowly perfused) compartment (see Figure 3 ) with an absorption half-time of $30 \mathrm{~min}$.

The final WQSM GSH-turnover model described predicts temporal and dose-dependent patterns of relative GSH content in liver, lung and kidney (Figure 7) all reasonably similar to corresponding patterns observed by Warren et al. (1982) (Figure 6). Figure 8 shows corresponding WQSM model predictions for mice and rats that continuously inhale naphthalene
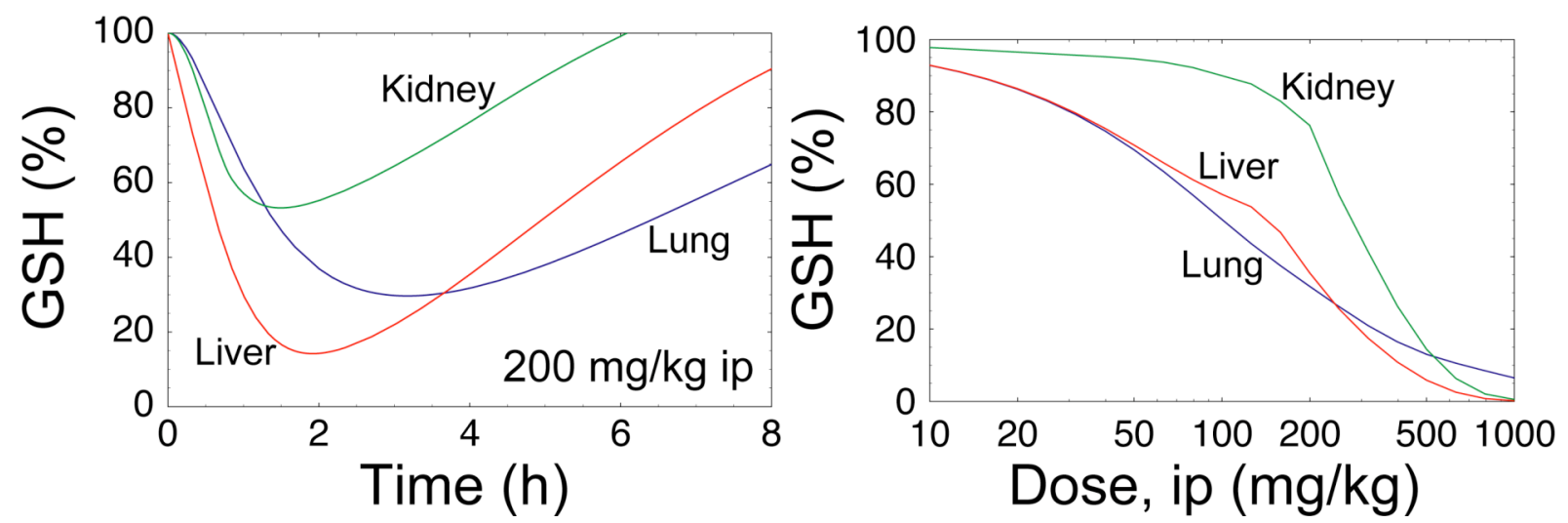

Figure 7. Glutathione (GSH) concentrations predicted by the WQSM model for 20- to 25-g male mice ip-injected with naphthalene, relative to those in vehicle-exposed animals, in liver (red), lung (blue) and kidney (green). (Left) GSH levels predicted in mice ip-injected with $200 \mathrm{mg} / \mathrm{kg}$ naphthalene as functions of post-injection time; (right) GSH levels $4 \mathrm{~h}$ after ip injection as functions of naphthalene dose.
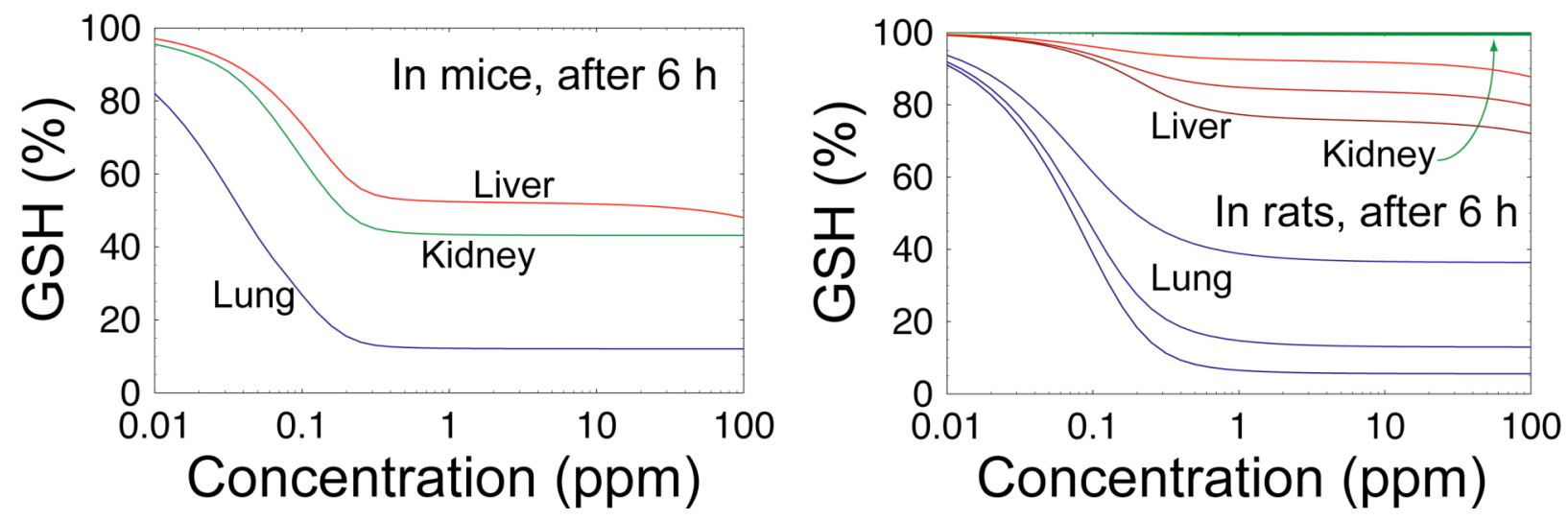

Figure 8. Glutathione (GSH) concentrations predicted by the WQSM model for 22.5-g male mice and for $0.5-\mathrm{kg}$ male rats exposed continuously for $6 \mathrm{~h}$ by inhaling the indicated air concentration of naphthalene, relative to those in vehicle-exposed animals, in liver (red), lung (blue) and kidney (green). In the plot for rats (right), in each set of red and blue curves, the lightest and uppermost curve corresponds to the base-case WQSM model, and the corresponding pair of progressively lower/darker curves reflect assumed increased maximum rates of CYP metabolism in lung by factors of 2 and 3 , respectively. 
at a specified air concentration for a total of 6-hour. This single-pulse respiratory exposure scenario yields results very similar to those obtained using the repeated-exposure scenario used in the mouse and rat bioassays done by NTP $(1992,2000)$. (As noted earlier in discussing Figure 4, although daily 6-hour exposures were used 5 days/week in those bioassays, the impact of repeated exposures on tissue-specific dynamic equilibria achieved is estimated to have been minimal.) For mice, the model predicts moderate GSH depletion in liver and kidney, and nearly complete GSH depletion in lung, at all naphthalene concentrations exceeding about $0.1 \mathrm{ppm}$ (Figure 8, left). Assuming nasal naphthalene concentrations achieved were similar to those in lung, and that nasal epithelial tissues in mice are at least as sensitive to naphthalene cytotoxicity as those in the lung, this pattern is consistent with substantial inflammation and evidence of cytotoxic/hyperplastic response observed in these tissues in some or nearly all bioassay mice at both exposure levels used, 10 and 30 ppm, with no such evidence in any other tissue at either exposure level (Abdo et al., 1992; NTP, 1992).

For rats, the WQSM model predicts that severe GSH depletion will not occur in kidney, liver or lung at any exposure level up to $100 \mathrm{ppm}$ naphthalene, which is consistent with absence of cytotoxic effects observed in any of these tissues in bioassay rats exposed daily to 6-hour levels of 10, 30 or 60 ppm naphthalene (NTP, 2000; Abdo et al., 2001; Long et al., 2003). The pattern of GSH response to 6-hour naphthalene exposures in rat lung (Figure 8, right) suggests that any rat tissue that might be exposed to concentrations similar to those in lung, but also produce reactive naphthalene metabolites more than about twice as rapidly as lung, would result in nearly complete GSH depletion, and thus be expected to incur cytotoxicity due to concurrent exposure to reactive naphthalene metabolites (e.g., 1,2- and/or 1,4-naphthoquinone) at naphthalene concentrations $\geq 1 \mathrm{ppm}$.

\subsection{Carcinogenic MOA for Naphthalene-Induced Nasal Tumors in Rats}

In the NTP rat bioassay, nearly all rats in all (10-, 30- and 60-ppm) exposure groups exhibited cytotoxic effects reflected by evident areas of cell killing, metaplasia, and mild to moderate hyperplasia in respiratory and olfactory nasal epithelia (NTP, 2000; Abdo et al., 2001; Long et al., 2003). These bioassay results, combined with corresponding histological observations (Section 2.1) and WQSM modeling results (Section 2.4), provide arguably convincing support for the hypothesis that: (a) a substantial subset of cells contained in rat 
respiratory and olfactory nasal epithelia (perhaps analogous to Clara cells in mouse bronchial epithelium) have a greater capacity to metabolize naphthalene to reactive intermediates than is present in rat lung tissue, and (b) metabolism in such tissues exposed for $6 \mathrm{~h}$ to $\geq 1 \mathrm{ppm}$ naphthalene will generate reactive metabolite levels that deplete GSH to levels low enough to render these metabolites cytotoxic. This hypothesis could be developed more explicitly and be tested by adapting for application to naphthalene PBPK models that incorporate nasal compartments and dynamic nasal tissue dosimetry (Anderson et al., 2000; Frederick et al., 2002; Sarangapani et al., 2002; Sweeny et al., 2004). Such models could be parameterized using species-specific data on GSH depletion and covalent binding in nasal tissues exposed in vivo to different naphthalene concentrations in air.

A recent EPA review of naphthalene toxicity illustrates how the "catch 22" Guidelines policy regarding potential DMOA carcinogens, referred to in Section 1, has applied in the case of this chemical carcinogen. The review states (USEPA, 2004, pp. 68-69):

"Tissue sites of nonneoplastic cellular damage (bronchoalveolar region in mice) show some correlation with tissue sites of carcinogenicity (lung tumors in mice, but not rats), suggesting that naphthalene metabolites may act by a nongenotoxic mode of action involving sustained cellular proliferation following cellular damage. However, an understanding of the mode of action is inadequate for determining why rats, but not mice, develop tumors originating in nasal epithelial tissue, even though both species show nonneoplastic lesions in nasal epithelial tissue following inhalation exposure to naphthalene. ... Available evidence in support of a nongenotoxic mode of action is inadequate to preclude a mode of action involving direct covalent modification of DNA ..." [emphasis added]

Thus, under the Guidelines, knowledge required to support a cytotoxic MOA must preclude the involvement of a genotoxic MOA, even if evidence supports non-negligible contribution of cytotoxicity-driven regenerative hyperplasia in amplifying whatever (if any) genotoxic component was involved in rat-nasal-tumor generation by naphthalene. The review implies that a cytotoxic MOA might be entertained if data could explain why NAP-induced cytotoxicity can cause nasal tumors in rats, but fails to do so in mice. But the species difference in this regard ignores specific histological evidence supporting the direct role of regenerative focal hyperplasia in promoting adjacent, histologically similar tumors in the nasal epithelium of NAP-exposed rats (Section 2.1). The strong likelihood of at least a DMOA (if not a purely cytotoxic MOA) was 
thus ignored in the risk-estimation method ultimately selected for risk extrapolation (USEPA, 2004). The resulting approach is not scientifically credible, for naphthalene-induced rat nasal tumors, because it denies wide recognition that regenerative hyperplasia can contribute to tumor promotion (Section 1). This position is not equivalent to suggesting that regenerative hyperplasia ought always to be assumed to increase tumor likelihood whenever and wherever it occurs. However, when this (or any other) specific basis for a nongenotoxic-MOA (i.e., for a likely DMOA) contribution to elevated risk is supported by specific data in a particular case, applying an unmodified default risk-extrapolation model that presumes a purely genotoxic MOA cannot not be justified scientifically.

\section{Biologically Based (MVK) Modeling to Bound MOA Uncertainty}

Biologically based stochastic 2-stage models of carcinogenesis provide a mechanistic framework for understanding and modeling the impact on cancer risk of dynamic exposures to environmental agents that affect rates of critical stem-cell mutations, and rates of stem-cell birth and/or death (Moolgavkar and Knudsen, 1981; Moolgavkar, 1983; Bogen, 1989). This framework is consistent with the large body of experimental and epidemiological data supporting the view that genotoxicity as well as altered cell-growth kinetics each play critical roles that may affect environmental carcinogen dose-response (Cohen and Ellwein, 1990, 1991; Ames and Gold, 1990; Ames et al., 1993; Hanahan and Weinberg, 2000) The "MVK" model of carcinogenesis (Moolgavkar, 1983) posits occurrence of incipient cancer cells as a doubly stochastic filtered Poisson process, whereby normal epithelial stem cells can each by mutation at mean rate $m_{1}$ give rise to a premalignant cell, which each may proliferate clonally (by cell division at birth rate $b$ and cell death/differentiation at rate $d$ ) or give rise by mutation at mean rate $m_{2}$ to a malignant cell. Stem cells likewise undergo cell birth and death/differentiation, which may affect the number $N$ of stem cells at risk for transformation over time. Corresponding background rates in stem cells shall be denoted using the subscript "o".

As mentioned above (Section 1), from an MVK-modeling perspective, dose-induced regenerative cell renewal may act to boost the net proliferation rate $(g=b-d)$ of surviving (and typically more resistant) premalignant cells exposed. The number of premalignant-cell populations depends in turn on the background rate $m_{\mathrm{o}}$ of critical mutations in these cells that, together with $g$, determine the spontaneous risk of tumor occurrence according to this model. 
How cytotoxicity and consequent regenerative cell renewal affect tumor risk thus depends critically on the value of the ratio discussed in Section 2.3 , namely $\rho=\mathrm{RR}_{\text {death }} / \mathrm{RR}_{\text {mut }} \propto$ $\left[b(\mathrm{D}) / b_{\mathrm{o}}\right] /\left[m(\mathrm{D}) / m_{\mathrm{o}}\right]$, in premalignant cells exposed to dose rate D. If $m_{\mathrm{o}}$ is very small, for example, regenerative hyperplasia alone (a purely cytotoxic MOA) may not boost $\rho$ enough to increase the background tumor rate in numbers of animals feasible to use in bioassay studies, unless $D$ is large and does not decrease the impact of $\rho$ by reducing $g$.

For application specifically to naphthalene-induced nasal tumors in rats, the 2-stage stochastic MVK model was applied assuming approximately constant $N$ for post-neonatal epithelial (excluding delayed-growth-phase, such as mammary) tissue, and equality among stagespecific background mutation rates (setting $m_{\mathrm{o}}=m_{1}=m_{2}$ at zero dose). The model was implemented as described below using piecewise-constant parameters, which during each $i$ th interval (for $i=1,2$ ) involve corresponding rates of mean occurrence $\left(N m_{i}\right)$, birth $\left(b_{i}\right)$, death $\left(d_{i}\right)$, and mutation $\left(m_{i}\right)$ of premalignant cells. The tumor data modeled were data concerning nasal respiratory epithelium adenomas (NREA) in male rats, and nasal olfactory epithelium neuroblastomas (NRON) in female rats, exposed to $60 \mathrm{ppm}$ naphthalene for 6 hours/day, 5 day/week beginning at 6 weeks of age, from the NTP (2000) bioassay discussed above. The highest (60-ppm) exposure level provides maximum power to compare model results with empirical survival data (summarized in Appendix C of USEPA, 2004), in view of substantial exposure-related mortality that occurred in both sexes in this exposure group. From historical data pertaining to occurrence of these tumors in control NTP rats (Copely, 2000; NTP, 2002; NTP 2006), the background incidence rate of NREA in male rats was estimated to be 2/4000 $(0.05 \%)$, while that of NRON in female (and male) rats was estimated to be less than $0 / 4000$, which for the purpose of this analysis was approximated as $0.01 \%$. These very low background rates of tumor incidence, combined with the lifetime (105-week) bioassay duration for rats, severely constrain biologically plausible parameterizations of any MVK model applied to explain tumor incidence rates observed in both the control and exposed animals. For each tumor type, this model can be applied under three alternative MOA assumptions (denoted by the indicated MOA type): (G) a purely genotoxic MOA (GMOA) driven by a dose-related change in $m$, (C) a purely nongenotoxic/cytotoxic MOA (CMOA) driven by a dose-related change in $b$ in response to induced killing and replacement of stem cells, or (D) a dual or mixed MOA (DMOA) involving joint/simultaneous operation of both MOA types G and C. Conditional on very low 
tumor background rates, the divergence in model predictions made by these different MOA assumptions can be used to assess the extent to which model G, in particular, may be implausible.

In the case of naphthalene-induced nasal tumors in rats, there is arguably convincing evidence that model $\mathrm{G}$ cannot possibly be true in a strict sense, based on the histological evidence of tumor-site-specific inflammation and hyperplasia in the rat nasal epithelium, detailed toxicokinetic data on naphthalene-metabolite cytotoxicity, in vitro data clearly implying that naphthalene-metabolite genotoxicity is invariably associated with increased likelihood of cell death in affected cell populations, and related PBPK modeling discussed above. However, evidence for naphthalene-metabolite genotoxicity likewise questions the plausibility of model C for naphthalene-induced rat nasal tumors. A lower bound on the magnitude of MOA uncertainty associated with model $\mathrm{C}$ can be obtained by comparing the elevated level of rat tumor risk to which all models (including $\mathrm{C}$ have been fit), to the reduced level of risk predicted by the most C-like of biologically plausible model-D fits made conditional on the absence of dose-related cytotoxic effects, which effects are not consistent with a (e.g., default regulatory GMOA) assumption and would be expected to be negligible at very low levels of environmental exposure.

To illustrate this idea of bounding uncertainty in naphthalene carcinogenic MOA using the MVK framework, the following biologically realistic assumptions were used concerning model parameter values and parameter interrelationships applicable to this compound. As mentioned above, equality was assumed for stage-specific background mutation rates $\left(m_{0}\right)$. Values of $N$ were presumed to be approximately $10^{8}$ for nasal epithelial stem cells of each tumor type. Biologically plausible values for $m_{0}$ were presumed to be between $10^{-8}$ and $10^{-7} \mathrm{y}^{-1}$, i.e., similar to estimated values pertaining to humans (Trainor et al., 1984; King et al., 1994; Mendelsohn, 1990; Robinson et al., 1994). The background rate $b_{0}$ of stem-cell division for nasal epithelium was assumed to be $1 \mathrm{y}^{-1}$, based on labeling indices $<1 \%$ observed in basal lamina that serve as stem-cell reservoirs for rat nasal epithelial tissues (Monticello et al., 1990; Hotchkiss et al., 1997). Potential linear functional dependence of $m$ on $b$, implied in the formal MVK model (Moolgavkar, 1983) and also by experimental evidence (Ames et al., 1993), was ignored here in view of the relatively minor quantitative impacts (of order $[\Delta b]^{2}$ ) such functional dependence can have, which in turn is due to relatively large impacts on risk that the MVK 
model predicts may arise from any relatively small (e.g., cytotoxicity-related) change $(\Delta b)$ in value(s) of $b$. Equal background rates of stem-cell birth and death were assumed, reflecting the assumed, approximately constant value of stem-cell number $N$ over the modeled post-natal rat lifespan (105 weeks). Premalignant cells generating NREA were assumed under normal conditions to proliferate at elevated rates of $n b_{0}$ assuming $n=5$, consistent with $n$-fold (hyperplastic) elevation in turnover rates with observed values of $n$ between 5 and 20 in putative premalignant cells that are histologically identifiable (Rotstein et al., 1986; Dragan et al., 1993; Zerban, 1994), as well as in nasal polyps (Coste et al., 1996). It was assumed that $n=1$ for premalignant cells generating NRON, consistent with the observation that neuroendocrine cells and associated neuroepithelial bodies in mouse bronchiolar epithelium show very little if any mitotic activity and appear to be relatively resistant to chemically induced cytotoxicity (Ogawa et al., 1993).

In all MVK models considered, premalignant cells in bioassay-exposed animals were assumed to be by some factor $K$ less sensitive to cell killing by reactive naphthalene metabolites, in accordance with observations that repeated inhalation exposures to the naphthalene produce airway-specific Clara Cell tolerance in mouse bronchiolar epithelium (West et al., 2000a-b, 2003). Such induced, airway-specific Clara Cell tolerance in mouse bronchiolar epithelium was previously observed after bromobenzene exposure (Ogawa et al., 1993), and is generally similar to exposure-induced resistance of hepatocytes to styrene toxicity observed to develop in B6C3F1 mice (Mahler et al., 1999), resistance of murine lung tumor cells to cytotoxicity induced by xenobiotics including naphthalene (Fokert et al., 1992), and resistance to cytotoxic drugs observed in leukemic cells (Maung et al., 1994). Intrinsic and/or induced heterogeneity in GSH levels appears to play an important role in NAP susceptibility of Clara cells (West et al., 2000ab), as has also observed as a basis for cytotoxic resistance in leukemic cells (Maung et al., 1994); however, one or more of many other known cellular strategies to reduce oxidative stress (Forsberg et al., 2001) may also be involved. In view of at least 4-fold variation observed in murine bronchiolar Clara-cell glutathione levels (West, 2000b), and absent more informative data on this point, a susceptibility-reduction factor of $K=10$ was assumed in this analysis. In view of the strong correlation between naphthalene-metabolite genotoxicity and cytotoxicity (Figure 2), the factor $K$ was assumed also to apply to exposure-induced mutation. 
In model $\mathrm{G}$, the mutation rate $m$ was assumed to increase over background rate $m_{0}$ by a dose-dependent factor $M$ in stem cells, and by the factor $[1+(M-1) / K]$ in premalignant cells, with $M=1$ for where $M=1$ under unexposed conditions. In model C, tissue response to doserelated cell killing was assumed to cause a birth-rate increase over background rate $b_{0}$ by a dosedependent factor $B$ in stem cells, and by the factor $[1+(B-1) / n]$ in premalignant cells, where $B=1$ under unexposed conditions. A background death rate $b_{0}$ assumed in stem and premalignant cells was assumed to increase $B$-fold in stem cells, and by the factor $[1+(B-1) /(n K)]$ in premalignant cells. In model $\mathrm{D}$, it was assumed that $\mathrm{C}$ - and $\mathrm{G}$-specific contributions to a DMOA are governed mechanistically by the empirical relationship between cytotoxicity and mutation, $B=\operatorname{Max}(1,1 /[0.5280-\log (M-1) / 13.358]$ plotted in Figure 2, based on in vitro data for the most potent mutagenic naphthalene metabolites yet identified, 1,2- and 1,4-naphthalene epoxide. Thus, no effects of dose-related stem-cell proliferation per se (e.g., on stem cell number) were incorporated in Model B, C or D. Model D* shall denote model D conditional on $B=1$, representing model $\mathrm{D}$ in the absence of any dose-related cytotoxic effect on MVK-model parameter $b$. Model $\mathrm{D}^{*}$ illustrates the magnitude of risk predicted by model $\mathrm{D}$ that is attributable only to mutagenic effects.

Models conditional on corresponding background-rate fits were fit to raw, observed highdose data for NREA and NRON incidence rates after first deleting data pertaining to animals that died before the occurrence of each corresponding tumor type (12/48 female NRON, 15/41 male NREA; from Appendix C of EPA, 2004) and adjusting to the corresponding "Poly-3" estimate of tumor incidence ( $28.2 \%$ female NRON, $38.1 \%$ male NREA; from p. 30 of NTP, 2002). The adjusted time-specific tumor-incidence rates were used to estimate the corresponding survival function for exposed animals with each tumor type. To fit each MOA-specific model to an adjusted, elevated tumor-incidence rate, a single corresponding MOA-specific parameter was optimized conditional on other parameter values considered biologically plausible as discussed above. Model calculations were performed using the analytic approach of Zheng (1995), implemented using Mathematica $5.0^{\circledR}$ software (Wolfram, 1999). Optimization in each case yielded a unique univariate model fit ( $m_{0}$ to fit background rates, and depending on model type, either $M$ and/or $B$ to fit elevated rates), conditional on fixed values of the other MVK parameters described above, since the MVK-type hazard function with at most three piecewise-constant parameters is identifiable (Heidenreich et al., 1997). 
Model fits obtained for each tumor type are summarized in Table 1 and plotted in Figure 9. Each tumor-specific plot shows that model G (blue curve) diverges greatly from model C (red curve), with model D generally falling between models $\mathrm{C}$ and $\mathrm{G}$ at all times points shown. Model D also appears to be somewhat more consistent with the empirical survival function for each tumor type. The value of model $D^{*}$ at week 105 indicates that a genotoxic component represents about $8.6 \%$ and $13.5 \%$ of the total tumor incidence explained by model D for NREA and for NRON, respectively.

Model D reflects a mechanistic explanation of the modeled bioassay results that is reasonably consistent with multistage cancer theory and the large amount of in vivo and in vitro toxicokinetic data that clearly establish that cytotoxicity did play some role in elevating the rates of nasal tumors observed in naphthalene-exposed rats. Figure 10 replots models D and D* for each tumor type as corresponding functions of additional (i.e., increased) mutagenic risk, $M-1$. The ratio of slopes for models $\mathrm{D}$ and $\mathrm{D}^{*}$ as $M \rightarrow 1$ thus represents, for each tumor type, a plausible lower bound on the magnitude of corresponding MOA-related uncertainty associated with any low-dose extrapolation that is premised on a genotoxic MOA, for cancer risk posed by naphthalene based on the modeled bioassay data. These slope ratios are 31 and 10.7 for NREA and NRON, respectively. It is emphasized that these factors address MOA-related uncertainty only, and do not address or in any way account for likely additional conservatism associated with linear, GMOA-based extrapolation of low-dose risk from the NTP rat tumor data without first adjusting for the pharmacokinetic relationship, in rodents and in humans, between (applied) naphthalene concentration and biologically effective dose (e.g., of 1,2- and/or 1,4naphthoqhinone adducts with DNA in putative stem cells) in susceptible target tissues. It is clear (e.g., from Figure 6) that for naphthalene this relationship is quite nonlinear, and likely is tightly related to corresponding target-cell-specific levels of glutathione depletion. Pharmacokinetic uncertainty for these tumor endpoints should be addressed separately by applying PBPK models after validation using relevant (including required new, tissue-specific) experimental data. However, the MVK-bounding approach illustrated above supports the application of MOAspecific uncertainty factors of about $1 / 30$ and $1 / 10$ to linearly extrapolated risk estimates from NTP rat bioassay data on NREA and NRON tumor endpoints, respectively, if such 
Table 1. Summary of MVK model fits to control and high-dose rat nasal tumor data.

\begin{tabular}{|lccccc|}
\hline \multirow{4}{*}{ Tumor type $^{a}$} & & & \multicolumn{3}{c|}{ Model parameters $^{b}$} \\
\cline { 3 - 6 } & & & & & \\
Exposure & group & Model(s) & $\left(\times 10^{-7}\right)$ & $M$ & $B$ \\
\hline \multirow{3}{*}{ NREA } & Control & All & 1.579 & 1 & 1 \\
& $60 \mathrm{ppm}$ & $\mathrm{G}$ & {$[1.579]$} & 118.8 & 1 \\
& $60 \mathrm{ppm}$ & $\mathrm{C}$ & {$[1.579]$} & 1 & 5.734 \\
& $60 \mathrm{ppm}$ & $\mathrm{D}$ & {$[1.579]$} & 27.99 & {$[2.982]$} \\
& & & & & \\
\multirow{4}{*}{ NRON } & Control & All & 7.004 & 1 & 1 \\
& $60 \mathrm{ppm}$ & $\mathrm{G}$ & {$[7.004]$} & 188.5 & 1 \\
& $60 \mathrm{ppm}$ & $\mathrm{C}$ & {$[7.004]$} & 1 & 7.983 \\
& $60 \mathrm{ppm}$ & $\mathrm{D}$ & {$[7.004]$} & 61.76 & {$[3.642]$} \\
\hline
\end{tabular}

${ }^{a}$ NREA $=$ nasal respiratory epithelium adenomas in male rats, NRON $=$ nasal olfactory epithelium neuroblastomas (NRON) in female rats.

${ }^{b}$ The single, parameter in each row is shown non-bracketed and to 4 significant digits was obtained conditional on all other parameters in that row. Note that in model $\mathrm{D}$, parameter $B$ is modeled as the dependent function of $M$ shown in Figure 2.
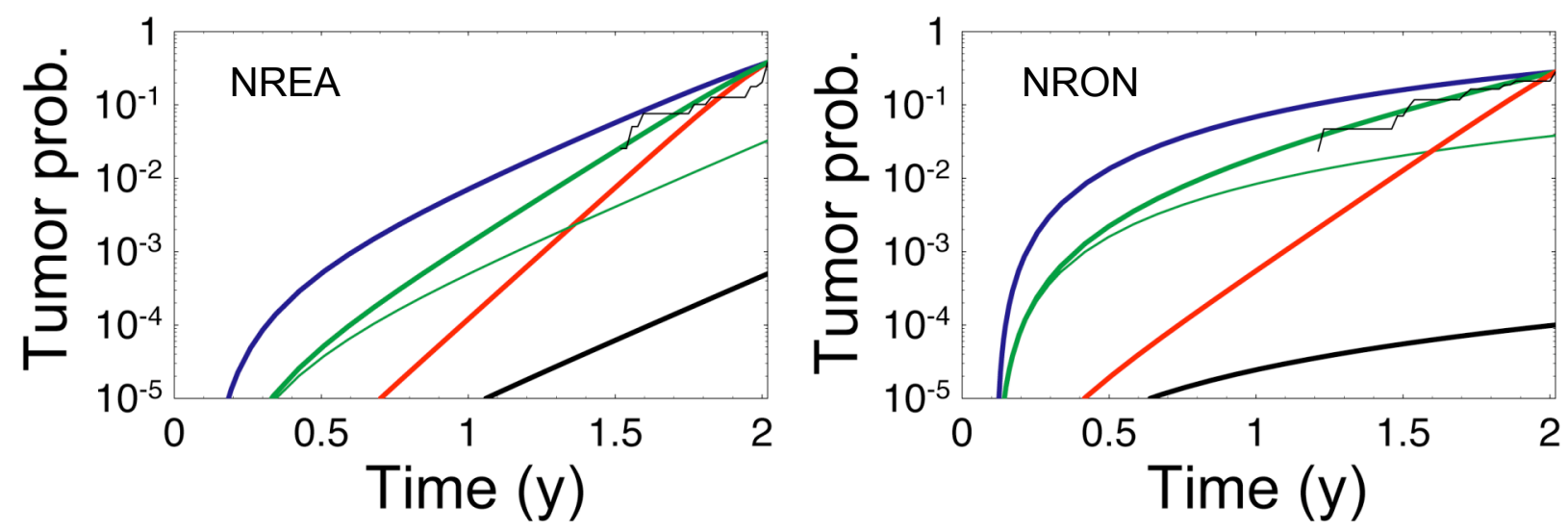

Figure 9. MOA-specific MVK models of NREA and NRON tumor incidence in NTP bioassay rats. In each plot, the bold black (lowermost) curve shows the baseline MVK model fit to the indicated control tumor incidence rate, to which baseline all of the models considered collapse at zero dose; the bold blue (uppermost), red and green curves show models G, C and D, respectively; and the light green curve shows model D*. The jagged light black step function is the approximate survival function based on corresponding adjusted empirical bioassay survival data. 

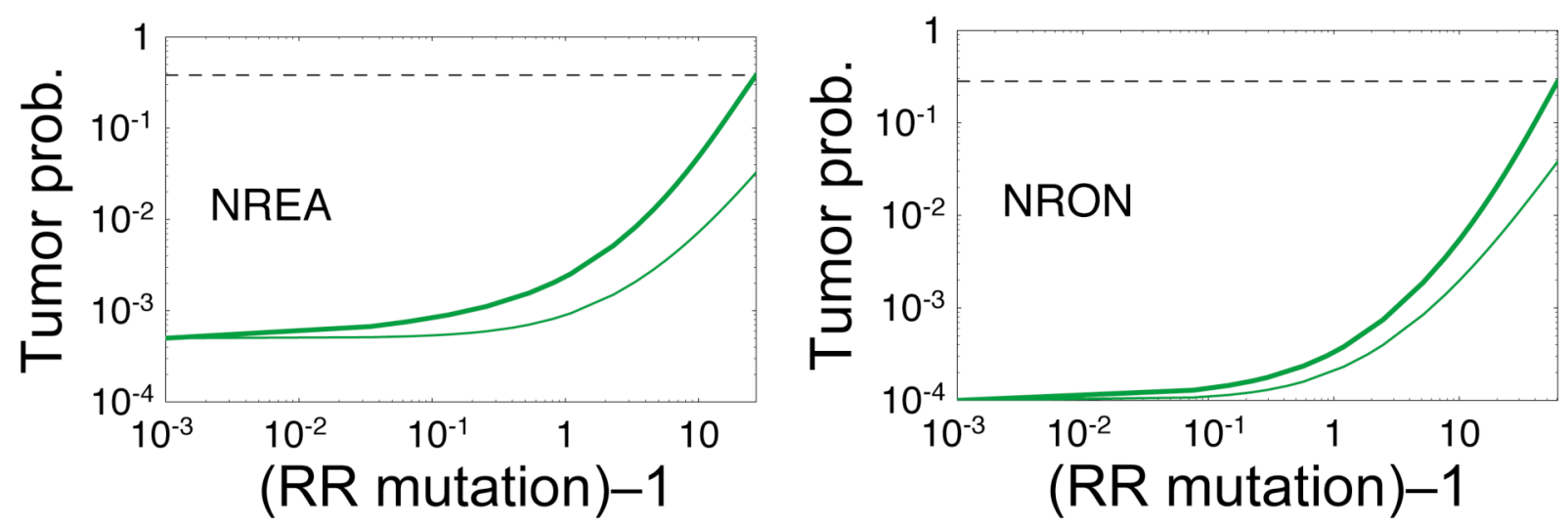

Figure 10. MOA-specific MVK models D (bold green curve) and D* (light green curve) of NREA and NRON tumor incidence in NTP bioassay rats, replotted from Figure 9 as a function of net relative mutagenic risk, $(M-1)$.

extrapolations (e.g., by default) presume a genotoxic MOA. Note that the MVK approach used did not involve any low-dose extrapolation model of tumor risk as a function of administered dose (i.e., bioassay concentration of naphthalene).

Within the range of plausible values of $m_{0}$ considered, different corresponding values of $N$ could be used to obtain the same MVK model fits, consistent with the Heidenreich et al. (1997) identifiability constraint. However, it was found that such small changes within this range affected neither fundamental MVK model behaviors nor their quantitative implications in a major way, nor corresponding conclusions reached. The models were, however, quite sensitive to values used for parameters $n, K$ and $b_{0}$, and conclusions reached must be interpreted with this sensitivity in mind, particularly insofar as improved estimates of these parameters could be obtained experimentally, using methods similar to those used to better understand the role of cell kinetics in formaldehyde-induced nasal tumors in rats (Monticello et al., 1996). The proposed approach could be extended to address multiple ( $>2)$ groups of bioassay data, e.g., using formal maximum likelihood methods.

\section{Discussion}

Bioassay data, supplemental toxicokinetic data, and related physiologically based pharmacokinetic and 2-stage stochastic carcinogenesis modeling results all clearly indicate that 
naphthalene is a DMOA carcinogen. Although genotoxicity associated with reactive naphthalene metabolites may theoretically contribute to increased risk at all doses, the USEPA Guidelines (2005) imply that for such a chemical, judgment be used to compare and assess approaches to low-level risk extrapolation based solely on models that posit either a genotoxic or a cytotoxic MOA, such as models $\mathrm{G}$ and $\mathrm{C}$ considered above. A DMOA approach (i.e., an approach involving a nongenotoxic MOA) is evidently allowed only when evidence is sufficient to fully parameterize a biologically based model that reliably extrapolates risk to low levels of concern. The Guidelines thus hinder consideration of MOA uncertainty when data are insufficient to parameterize such a model, but otherwise clearly support a DMOA. In the case of naphthalene-induced rat nasal tumors, it was shown that a bounding factor approach — similar to that used in reference dose procedures for classic toxicity endpoints - can address MOA uncertainty in a way that avoids explicit modeling of low-dose risk as a function of administered or internal dose. Even though data are not yet sufficient to fully validate a "nonlinear" toxicokinetic model for naphthalene, implications of DMOA uncertainty on low-dose risk could be bounded with reasonable confidence because the target tumor types involved happen to be extremely rare. Plausibility bounds on rat-tumor-type specific DMOA-related uncertainty were obtained using a 2-stage model adapted to reflect the empirical link between genotoxic and cytotoxic effects of the most potent identified genotoxic naphthalene metabolites, 1,2- and 1,4naphthoquinone. Resulting bounds each provided the basis for a corresponding "uncertainty" factor between $1 / 30$ and 1/10 appropriate to apply to estimates of naphthalene risk obtained by linear extrapolation under a default genotoxic MOA assumption. This procedure merits exploration as a way to address MOA uncertainty for other DMOA carcinogens. 


\section{APPENDIX}

\section{Excerpts from the USEPA (2005) Guidelines for Carcinogen Risk Assessment}

\subsection{ANALYSES IN THE RANGE OF OBSERVATION. 3.2.2. Toxicodynamic ("Biologically Based") Modeling.}

... It is possible for different models to provide equivalent fits to the observed data but to diverge substantially in their projections at lower doses. When model parameters are estimated from tumor incidence data, it is often the case that different combinations of parameter estimates can yield similar results in the observed range. For this reason, critical parameters (e.g., mutation rates and cell birth and death rates) are estimated from laboratory studies and not by curve-fitting to tumor incidence data (Portier, 1987). This approach reduces model uncertainty (see Section 3.6) and ensures that the model does not give answers that are biologically unrealistic.... Toxicodynamic modeling can provide insight into the relationship between tumors and key precursor events. For example, a model that includes cell proliferation can be used to explore the extent to which small increases in the cell proliferation rate can lead to large lifetime tumor incidences (Gaylor and Zheng, 1996). [p. 3-14]

\subsection{EXTRAPOLATION TO LOWER DOSES. \\ 3.3.1. Choosing an Extrapolation Approach}

The approach for extrapolation below the observed data considers the understanding of the agent's mode of action at each tumor site (see Section 2.4). Mode of action information can suggest the likely shape of the dose-response curve at lower doses. The extent of inter-individual variation is also considered, with greater variation spreading the response over a wider range of doses.

Linear extrapolation should be used when there are MOA data to indicate that the doseresponse curve is expected to have a linear component below the POD. Agents that are generally considered to be linear in this region include:

- agents that are DNA-reactive and have direct mutagenic activity, ...

When the weight of evidence evaluation of all available data are insufficient to establish the mode of action for a tumor site and when scientifically plausible based on the available data, linear extrapolation is used as a default approach, because linear extrapolation generally is considered to be a health-protective approach. Nonlinear approaches generally should not be used in cases where the mode of action has not been ascertained. Where alternative approaches with significant biological support are available for the same tumor response and no scientific consensus favors a single approach, an assessment may present results based on more than one approach

A nonlinear approach should be selected when there are sufficient data to ascertain the mode of action and conclude that it is not linear at low doses and the agent does not demonstrate mutagenic or other activity consistent with linearity at low doses. Special attention is important when the data support a nonlinear mode of action but there is also a suggestion of mutagenicity. Depending on the strength of the suggestion of mutagenicity, the assessment may justify a conclusion that mutagenicity is not operative at low doses and focus on a nonlinear approach, or alternatively, the assessment may use both linear and nonlinear approaches.

Both linear and nonlinear approaches may be used when there are multiple modes of action. If there are multiple tumor sites, one with a linear and another with a nonlinear mode of 
action, then the corresponding approach is used at each site. If there are multiple modes of action at a single tumor site, one linear and another nonlinear, then both approaches are used to decouple and consider the respective contributions of each mode of action in different dose ranges. For example, an agent can act predominantly through cytotoxicity at high doses and through mutagenicity at lower doses where cytotoxicity does not occur. Modeling to a low response level can be useful for estimating the response at doses where the high-dose mode of action would be less important. [pp, 3-21 - 3-22, emphasis added]

\subsubsection{Extrapolation Using a Toxicodynamic Model}

The preferred approach is to develop a toxicodynamic model of the agent's mode of action and use that model for extrapolation to lower doses (see Section 3.2.2). The extent of extrapolation is governed by an analysis of model uncertainty, where alternative models that fit similarly in the observed range can diverge below that range (see Section 3.6). Substantial divergence is likely when model parameters are estimated from tumor incidence data, so that different combinations of parameter estimates yield similar fits in the observed range but have different implications at lower doses. An analysis of model uncertainty can be used to determine the range where extrapolation using the toxicodynamic model is supported and where further extrapolation would be based on either a linear or a nonlinear default, as appropriate (see Sections 3.3.3, 3.3.4). [p. 3-22]

\subsubsection{Extrapolation Using a Low-dose, Linear Model}

Linear extrapolation should be used in two distinct circumstances: (1) when there are data to indicate that the dose-response curve has a linear component below the POD, or (2) as a default for a tumor site where the mode of action is not established (see Section 3.3.1). For linear extrapolation, a line should be drawn from the POD to the origin, corrected for background. [p. 3-23]

\subsubsection{Nonlinear Extrapolation to Lower Doses}

A nonlinear extrapolation method can be used for cases with sufficient data to ascertain the mode of action and to conclude that it is not linear at low doses but with not enough data to support a toxicodynamic model that may be either nonlinear or linear at low doses. Nonlinear extrapolation having a significant biological support may be presented in addition to a linear approach when the available data and a weight of evidence evaluation support a nonlinear approach, but the data are not strong enough to ascertain the mode of action applying the Agency's mode of action framework. If the mode of action and other information can support chemical-specific modeling at low doses, it is preferable to default procedures.

For cases where the tumors arise through a nonlinear mode of action, an oral reference dose or an inhalation reference concentration, or both, should be developed in accordance with EPA's established practice for developing such values [involving application of "uncertainty factors" to Benchmark, no-observed-effect or lowest-observed-effect dose levels], taking into consideration the factors summarized in the characterization of the POD (see Section 3.2.5). [p. 3-23-3-24]

\subsubsection{Comparing and Combining Multiple Extrapolations \\ When multiple estimates can be developed, all datasets should be considered and a judgment made about how best to represent the human cancer risk. [p. 3-24]}




\section{References}

Abdo KM, SL Eustis, M McDonald, MP Jokinen, B Adkins Jr., JK Haseman. 1992. Naphthalene: a respiratory tract toxicant and carcinogen for mice. Inhalation Toxicol. 4:393409.

Abdo KM, S Grumbein, BJ Chou, R Herbert. 2001. F344 rats following 2 years of whole-body exposure to naphthalene vapors. Inhalation Toxicol. 13:931-950.

Adkins KM, EW Van Stee, JE Simmons, SL Eustis. 1986. Oncogenic response of strain A/J mice to inhaled chemicals. Toxicol. Environ. Health 17:311-322.

Ajao OG, MO Adenuga, JK Ladipo. 1988 Colorectal carcinoma in patients under the age of 30 years: a review of 11 cases. J. Roy. Coll. Surg. Edinburgh 33:277-279.

Arfsten DP, R Davenport, DJ Schaeffer. 1994. Reversion of bioluminescent bacteria (Mutatoхтм) to their luminescent state upon exposure to organic compounds, munitions, and metal salts. Biomed. Environ Sci. 7:144-149.

Agency for Toxicological Substance Disease Registry (ATSDR). 2005. Toxicological Profile for Naphthalene, 1-Methylnaphthalene, and 2-Methylnaphthalene. August 2005. U.S. Department of Health and Human Services, Public Health Service, ATSDR, Atlanta, GA.

Ames BN, LS Gold. 1990. Chemical carcinogenesis: Too many rodent carcinogens. Proc. Natl. Acad. Sci. 87:7772-7776.

Ames BN, MK Shigenaga, LS Gold. 1993. DNA lesions, inducible DNA repair, and cell division: Three key factors in mutagenesis and carcinogenesis. Environ. Health Perspect. 101:35-44.

Andersen M, R Sarangapani, R Gentry, H Clewell, T Covington, CB Frederick. 2000. Application of a hybrid CFD-PBPK nasal dosimetry model in an inhalation risk assessment: An example with acrylic acid. Toxicol. Sci. 57:312-325.

Baldwin RM, WT Jewell, MV Fanucchi, CG Plopper, AR Buckpitt. 2004. Comparison of pulmonary/nasal CYP2F expression levels in rodents and Rhesus Macaque. J. Pharmacol. Exp. Ther. 309:127-136.

Bogen KT. 1989. Cell proliferation kinetics and multistage cancer risk models. J. Natl. Cancer Inst. 81:267-277.

Bogen KT. 1990. Risk extrapolation for chlorinated methanes as promoters vs initiators of multistage carcinogenesis. Fund. Appl. Toxicol. 15:536-557.

Boland B, CY Lin, D Morin, L Miller, C Plopper, A Buckpitt. 2004. Site-specific metabolism of naphthalene and 1-nitronaphthalene in dissected airways of rhesus macaques. J. Pharmacol. Exp. Ther. 310(2):546-554.

Brunius G. 1987. Mitogenic activity of chloroform and carbon tetrachloride in serum-deficient or calcium-deficient cultures of human embryonic lung fibroblasts. Carcinogenesis 8(11):16451649.

Buckpitt AR, DL Warren. 1983. Evidence for hepatic formation, export and covalent binding of reactive naphthalene metabolites in extrahepatic tissues in vivo. J. Pharmacol. Exp. Ther. 225:8-16.

Bucher JR, Huff JE, Jokinen MP, Haseman JK, Stedham M, and Cholakis JM. 1991. Inhalation 
of tetranitromethane causes nasal passage irritation and pulmonary carcinogenesis in rodents. Cancer Lett. 57:95-101.

Buckpitt AR, LS Bahnson. 1986. Naphthalene metabolism by human lung microsomal enzymes. Toxicol. 41:331-341.

Buckpitt AR, RB Franklin. 1989. Relationship of naphthalene and 2-methylnaphthalene metabolism to pulmonary bronchiolar epithelial cell necrosis. Pharm. Ther. 41:393-410.

Buckpitt A, M Buonarati, LB Avey, AM Chang, D Morin, CG Plopper. 1992. Relationship of cytochrome P-450 activity to Clara cell cytotoxicity. II. Comparison of stereoselectivity of naphthalene epoxidation in lung and nasal mucosa of mouse, hamster, rat, and rhesus monkey. J. Pharmacol. Exp. Ther. 261(1):364-372.

Buckpitt A, AM Chang, A Weir, L Van Winkle, X Duan, R Philpot, C Plopper. 1995. Relationship of cytochrome P-450 activity to Clara cell cytotoxicity. IV. Metabolism of naphthalene and naphthalene oxide in microdissected airways from mice, rats, and hamsters. Molec. Pharmacol. 47(1):74-81.

Buckpitt A, B Boland, M Isbell, M Shultz, R Baldwin, K Chan, A Karlsson, C Lin, A Taff, J West, M Fanucchi, L Van Winkle, C Plopper. 2002. Naphthalene-induced respiratory tract toxicity: metabolic mechanisms of toxicity. Drug Metab. Rev. 34(4):791-820.

Carrol RJ, and D Ruppert. 1988. Transformation and Weighting in Regression. Chapman and Hall, New York, NY.

Chichester CH, AR Buckpitt, A Chang, CG Plopper. 1993. Metabolism and cytotoxicity of naphthalene and its metabolites in isolated murine Clara cells. Molec. Pharmacol. 45:664672.

Cho TM, RL Rose, E Hodgson. 2006. In vitro metabolism of naphthalene by human liver microsomal cytochrome P450 enzymes. Drug Metab. Disposition 34:176-183.

Ciaccio PJ, Gicquel E, O'Neill PJ, Scribner HE, Vandenberghe YL. 1998. Investigation of the positive response of ethyl acrylate in the mouse lymphoma genotoxicity assay. Toxicol. Sci. 46:324-332.

Cohen SM, LB Ellwein. 1990. Cell proliferation in carcinogenesis. Science 249:1007-1011.

Cohen SM, LB Ellwein. 1991. Genetic errors, cell proliferation, and carcinogenesis. Cancer Res. 51:6493-6505.

Columbano A, Ledda-Columbano GM, Ennas MG, Curto M, Chelo A, Pani P. 1990. Cell proliferation and promotion of rat liver carcinogenesis: different effects of hepatic regeneration and mitogen induced hyperplasia on the development of enzyme altered foci. Carcinogenesis 11:771-776.

Conolly RB, Kimbell JS, Janszen D, Schlosser PM, Kalisak D, Preston J, Miller FJ. 2004. Human respiratory tract cancer risks of inhaled formaldehyde: dose-response predictions derived from biologically-motivated computational modeling of a combined rodent and human dataset. Toxicol. Sci. 82(1):279-296.

Coste A, JG Rateau, F Roudot-Thoraval, C Chapelin, L Gilain, Poron F, R Peynegre, JF Bernaudin, E Escudier. 1996. Increased epithelial cell proliferation in nasal polyps. Arch. Otolaryngol. Head Neck Surg. 122(4):432-436. 
Dass PD, EW Bermes Jr., EW Holmes. 1992. Renal and hepatic output of glutathione in plasma and whole blood. Biochim. Biophys. Acta 1156:99-102.

Dietrich DR, Swenberg JA. 1991. Preneoplastic lesions in rodent kidney induced spontaneously or by non-genotoxic agents: Predictive nature and comparison to lesions induced by genotoxic carcinogens. Mutat. Res. 248:239-260.

Ding X, LS Kaminsky. 2003. Human extrahepatic cytochromes P450: Function in xenobiotic metabolism and tissue-selective chemical toxicity in the respiratory and gastrointestinal tracts. Ann. Rev. Pharmacol. Toxicol. 43:149-173.

Dragan YP, J Hully, R Crow, M Mass, HC Pitot. 1994. Incorporation of bromodeoxyuridine in glutathione S-transferase-positive hepatocytes during rat multistage hepatocarcinogenesis. Carcinogenesis 15:1939-1947.

Duan X, C Plopper, P Brennan, A Buckpitt. 1996. Rates of glutathione synthesis in lung subcompartments of mice and monkeys: Possible role in species and site selective injury. $J$. Pharmacol. Exp. Ther. 277:1402-1409.

Estonius M, L Forsberg, O Danilsson, R Weinander, MJ Kelner, R Morgenstern. 1999. Distribution of microsomal glutathione transferase 1 in mammalian tissues: A predominant alternate first exon in human tissues. Eur. J. Biochem. 260:409-413.

Farber E. 1984. The multistep nature of cancer development. Cancer Res. 44:4217-4223.

Farber E, R Cameron.1984. The sequential analysis of cancer development. Adv. Cancer Res. $31: 125-226$.

Farooqui MYH, AE Ahmed. 1984. Circadian periodicity of tissue glutathione and its relationship with lipid peroxidation in rats. Life Sci. 34:2413-2418.

Flowers-Geary L, W Bleczinski, RG Harvey, TM Penning. 1996. Cytotoxicity and mutagenicity of polycyclic aromatic hydrocarbon o-quinones produced by dihydrodiol dehydrogenase. Chem.-Biol. Interact. 99:55-72.

Forkert PG, A Parkinson, LG Thaete, AM Malkinson. 1992. Resistance of murine lung tumors to xenobiotic-induced cytotoxicity. Cancer Res. 52:6797-6803.

Forsberg L, U de Faire, R Morgenstern. 2001. Oxidative stress, human genetic variation, and disease. Arch. Biochem. Biophys. 389(1):84-93.

Frederick CB, LG Lomax, KA Black, L Finch, HE Scribner, JS Kimbell, KT Morgan, RP Subramaniam, JB Marshall. 2002. A hybrid computational fluid dynamics and physiologically based inhalation model for interspecies dosimetry comparisons of ester vapors. Toxicol. Appl. Pharmacol. 183:23-40.

Gaylor DW, Zheng Q. 1996. Risk assessment of nongenotoxic carcinogens based on cell proliferation/death rates in rodents. Risk Anal. 16(2):221-225.

Ghanayem BI, Maronpot RR, Matthews HB. 1986. Association of chemically induced forestomach cell proliferation and carcinogenesis. Cancer Lett. 32(3):271-278.

Ghanem A, ML Shuler. 2000. Combining cell culture analogue reactor designs and PBPK models to probe mechanisms of naphthalene toxicity. Biotechnol. Prog. 16(3):334-345.

Hanahan D, RA Weinberg. 2000. The hallmarks of cancer. Cell 100:57-70.

Heidenreich WF, EG Luebeck, SH Moolgavkar, 1997. Some properties of the hazard function of the two-mutation clonal expansion model. Risk Anal., 17:391-399. 
Hengstler JG, Bogdanffy MS, Bolt HM, Oesch F. 2003. Challenging dogma: Thresholds for genotoxic carcinogens? The case of vinyl acetate. Ann. Rev. Pharmacol. Toxicol. 43:485-520.

Holmes TJ, Rainsford KD. 2002. Differential effects of non-genotoxic carcinogens and proliferating agents on cell growth, survival and apoptosis in hepatic cells in vitro. Life Sci. 69(25-26):2975-2992.

Hotchkiss JA, JR Harkema, NF Johnson. 1997. Kinetics of nasal epithelial cell loss and proliferation in F344 rats following a single exposure to $0.5 \mathrm{ppm}$ ozone. Toxicol. Appl. Pharmacol. 143:75-82.

International Agency for Research on Cancer (IARC). 2002. Traditional Herbal Medicines, Some Mycotoxins, Naphthalene and Styrene. IARC Monographs on the Evaluation of Carcinogenic Risks to Humans, vol. 82. World Health Organization, IARC, Lyon, France.

International Agency for Research on Cancer (IARC). 2003. Predictive Value of Rodent Forestomach and Gastric Neuroendocrine Tumors in Evaluating Carcinogenic Risks to Humans: Views and Expert Opinions of an IARC Working Group. IARC Technical Report No. 39. World Health Organization, IARC, Lyon, France.

King CM, ES Gillespie, PG McKenna, YA Barnett. 1994. An investigation of mutation as a function of age in humans. Mutat. Res. 316:79-90.

Kitteringham NR, C Davis C, N Howard, M Pirmohamed, BK Park. 1996. Interindividual and interspecies variation in hepatic microsomal epoxide hydrolase activity: studies with cisstilbene oxide, carbamazepine 10,11-epoxide and naphthalene. J. Pharmacol. Exp. Ther. 278:1018-1027.

Kohn MC. 1997. The importance of anatomical realism for validation of physiological models of disposition of inhaled toxicants. Toxicol. Appl. Pharmacol. 147:448-458.

Kohn MC, RL Melnick. 2000. The priviledged access model of 1,3-butadiene disposition. Environ. Health Perspect. Suppl. 108(S5):911-917.

Kotsanis N, Metcalfe CD. 1991. Enhancement of hepatocarcinogenesis in rainbow trout with carbon tetrachloride. Bull. Environ. Contam. Toxicol. 46:879-886.

Kup W. 1978. [Work-related origin of cancer in the nose, mouth, throat, and larynx.] Akad. Wiss. 2:20-25 (original in German, cited in NTP 1992 and abstracted in Carcinogenesis Abstracts).

Lanza DL, E Code, CL Crespi, FJ Gonzalez, GS Yost. 1999. Specific dehydrogenation of 3methylindole and epoxidation of naphthalene by recombinant human CYP2F1 expressed in lymphoblastoid cells. Drug Metab. Disposition 27:798-803.

Larson JL, Wolf DC, Butterworth BE. 1994. Induced cytotoxicity and cell proliferation in the hepatocarcinogenicity of chloroform in female B6C3F1 mice: comparison of administration by gavage in corn oil vs ad libitum in drinking water. Fundam. Appl. Toxicol. 22:90-102.

Lash LH. 2005. Role of glutathione transport processes in kidney function. Toxicol. Appl. Pharmacol. 204:329-342.

Lohr JW, GR. Willsky, MA Acara. 1998. Renal drug metabolism. Pharmacol. Rev. 50:107-141.

Long PH, RA Herbert, JC Peckham, SL Grumbein, CC Shackelford, K Adbo. 2003. Morphology of nasal lesions in F344/N rats following chronic inhalation exposure to naphthalene vapors. Toxicol. Pathol. 31 :655-664.

Mahler JF, HC Price Jr., RW O’Connor, RE Wilson, SR Eldridge, MP Moorman, DL Morgan. 
1999. Characterization of hepatocellular resistance and susceptibility to styrene toxicity in B6C3F1 mice. Toxicol. Sci. 48:123-133.

Mahvi D, H Bank, R Harley. 1977. Morphology of naphthalene-induced bronchiolar lesion. Am. J. Pathol. 86:559-566.

Maung ZT, L Hogarth, MM Reid, SJ Proctor, PJ Hamilton, AG Hall. 1994. Raised intracellular glutathione levels correlate with in vitro resistance to cytotoxic drugs in leukaemic cells from patients with acute lymphoblastic leukemia. Leukemia 8(9):1487-1491.

Mendelsohn, M. L. 1990. The somatic mutational component of human carcinogenesis. In: S. H. Moolgavkar (ed.), Scientific Issues in Quantitative Cancer Risk Assessment. Kirkhäuser, Boston.

Moolgavkar SH, 1983. Model for human carcinogenesis: Action of environmental agents. Environ. Health Perspect. 50:285-291.

Moolgavkar SH, AG Knudson. 1981. Mutation and cancer: A model for human carcinogenesis. J. Natl. Cancer Inst. 66:1037-1052.

Monticello TM, KT Morgan, ME Hurrt. 1990. Unit length as Marked goblet cell hyperplasia with mucus accumulation in the airways the denominator for quantitation of cell proliferation in nasal epithelia. Toxicol. Pathol. 18:24-31.

Monticello TM, KT Morgan, ME Hurrt. 1990. Unit length as Marked goblet cell hyperplasia with mucus accumulation in the airways the denominator for quantitation of cell proliferation in nasal epithelia. Toxicol. Pathol. 18:24-31.

Monticello TM, JA Swenberg, EA Gross, JR Leininger, JS Kimbell, S Seilkop,TB Starr, JE Gibson, KT Morgan. 1996. Correlation of regional and nonlinear formaldehyde-induced nasal cancer with proliferating populations of cells. Cancer Res. 56:1012-1022.

Murata M, Kurimoto S, Kawanishi S. 2006. Tyrosine-dependent oxidative DNA damage induced by carcinogenic tetranitromethane. Chem. Res. Toxicol. 19(10):1379-1385.

National Toxicology Program (NTP). 1992. Toxicology and Carcinogenesis Studies of Naphthalene in B6C3F1 mice (Inhalation Studies). Technical Report Series No 410. NTP, Research Triangle Park, NC.

National Toxicology Program (NTP). 2000. Toxicology and Carcinogenesis Studies of Naphthalene (CAS No. 91-20-3) in F344/N Rats (Inhalation Studies). Technical Report Series No 500. NTP, Research Triangle Park, NC.

National Toxicology Program (NTP). 2002. Report on Carcinogens Background Document for Naphthalene. NTP, Research Triangle Park, NC. http://ntpserver.niehs.nih.gov/newhomeroc/roc11/NaphthalenePub.pdf.

National Toxicology Program (NTP). 2006. NTP Historical Controls Report: All Routes and Vehicles, Rats. June 2006.

O'Brien KAF, LL Smith, GM Cohen. 1985. Differences in naphthalene-induced toxicity in the mouse and rat. Chem. Biol. Interact. 55:109-122.

O’Brien KA, C Suverkropp, S Kanekal, CG Plopper, AR Buckpitt. 1989. Tolerance to multiple doses of the pulmonary toxicant, naphthalene. Toxicol. Appl. Pharmacol. 99(3):487-500.

Ogawa T, M Tsubakihara, M Ichikawa, M Kanisawa. 1993. An autoradiographic study of the renewal of mouse bronchial epithelium following bromobenzene exposure. Toxicol. Pathol. 
21(6):547-553.

Phimister AJ, MG Lee, D Morin, AR Buckpitt, CG Plopper. 2004. Glutathione depletion is a major determinant of inhaled respiratory toxicity and naphthalene metabolism. Toxicol. Sci. $82: 268-278$.

Phimister AJ, KJ Williams, LS Van Winkle, CG Plopper. 2005. Consequences of abrupt glutathione depletion in murine Clara cells: Ultrastructural and biochemical investigations into the role of glutathione loss in naphthalene cytotoxicity. J. Pharmacol. Exp. Ther. 314:506-513.

Pitot HC, H Hikita, Y Dragan, L Sargent, M Haas. 2000. The stages of gastrointestinal carcinogenesis - application of rodent models to human disease. Alimentary Pharmacol. Ther. 14(Suppl. 1):153-160.

Plopper CG, C Suverkropp, D Morin, S Nishio, A Buckpitt. 1992. Relationship of cytochrome P-450 activity to Clara cell cytotoxicity. I. Histopathologic comparison of the respiratory tract in mice, rats and hamsters after parenteral administration of naphthalene. J. Pharmacol. Exp. Ther. 261(1):353-363.

Plopper CG, LS Van Winkle, MV Fanucchi, SRC Malburg, SJ Nishio, A Chang, AR Buckpitt. 2001. Early events in naphthalene-induced acute clara cell toxicity: 11. Comparison of glutathione depletion and histopathology by airway location. Am. J. Respir. Cell Molec. Biol. 24:272-281.

Portier C. 1987. Statistical properties of a two-stage model of carcinogenesis. Environ. Health Perspect. 76:125-131.

Quick DJ, ML Shuler. 1999. Use of in vitro data for construction of a physiologically based pharmacokinetic model for naphthalene in rats and mice to probe species differences. Biotechnol. Prog. 15(3):540-555.

Raunio H, J Hakkola, J Hukkanen, A Lassila, K Paivarinta, O Pelkonen, S Anttila, R Piipari, A Boobis, RJ Edwards. 1999. Expression of xenobiotic-metabolizing CYPs in human pulmonary tissue. Exp. Toxicol. Pathol. 51:412-417.

Robinson DR, K Goodall, RJ Albertini, JP O’Neill, B Finette, M Sala-Trepat, E Moustacchi, AD Tates, DM Beare, MHL Green, J Cole. 1994. An analysis of in vivo hprt mutant frequency in circulating T-lymphocytes in the normal human population: A comparison of four datasets. Mutat. Res. 313:227-247.

Rodgers IS, Baetcke KP. 1993. Interpretation of male rat renal tubule tumors. Environ. Health Perspect. 101(Suppl. 6): 45-52.

Rotstein J, DSR Sarma, E Farber. 1986. Sequential alterations in growth control and cell dynamics of rat hepatocytes in early precancerous steps in hepatocarcinogenesis. Cancer Res. 46:2377-2385.

Sanchez-Perez Y, C Carrasco-Legleu, C Garcia-Cuellar, J Perez-Carreon, S Hernandez-Garcia, M Salcido-Neyoy, L Aleman-Lazarini, S Villa-Trevino. 2005. Oxidative stress in carcinogenesis. Correlation between lipid peroxidation and induction of preneoplastic lesions in rat hepatocarcinogenesis. Cancer Lett. 217(1):25-32. 
Sanderson BJS, KJ Johnson, D Henner. 1991. Dose-dependent cytotoxic and mutagenic effects of antineoplastic alkylating agents on human lymphoblastoid cells. Environ. Molec. Mutagen. $17: 238-243$.

Sarangapani R, JG Teeguarden, G Cruzan, HJ Clewell, ME Andersen. 2002. Physiologically based pharmacokinetic modeling of styrene and styrene oxide respiratory-tract dosimetry in rodents and humans. Inhalation Toxicol.14(8):789-834.

Sasaki, JC, Arey J, Eastmond, DA, Parks KK, Grosovsky AJ. 1997. Genotoxicity induced in human lymphoblasts by atmospheric reaction products of naphthalene and phenanthrene. Mutat. Res. 393:23-35.

Schreiner CA. 2003. Genetic toxicity of naphthalene: A review. J. Toxicol. Environ. Health B, Crit. Rev. 6(2):161-183.

Schulte-Hermann R, Timmermann-Trosiener I, Schuppler J. Promotion of spontaneous preneoplastic cells in rat liver as a possible explanation of tumor production by nonmutagenic compounds. 1983. Cancer Res. 43:839-844.

Solt DB, Cayoma E, Tsuda H, Enomoto K, Lee G, Farber E. 1983. Promotion of liver cancer development by brief exposure to dietary 2-acetylaminofluorene plus partial hepatectomy or $\mathrm{CCl}_{4}$. Cancer Res. 43:188-191.

Stewart RD. 2001. Two-lesion kinetic model of double-strand break rejoining and cell killing Radiat. Res. 156:365-378.

Suerbaum S, Michetti P. 2002. Helicobacter pylori infection. N. Engl. J. Med. 347(15):11751186.

Sweeney LM, ML Shuler, DJ Quick, JG Babish. 1996. A preliminary physiologically based pharmacokinetic model for naphthalene and naphthalene oxide in mice and rats. Ann. Biomed. Eng. 24:305-320.

Sweeney LM, ME Andersen, ML Gargas. 2004. Ethyl acrylate risk assessment with a hybrid computational fluid dynamics and physiologically based nasal dosimetry model. Toxicol. Sci. 79:394-403.

Thornton-Manning JR, AR Dahl. 1997. Metabolic capacity of nasal tissue interspecies comparisons of xenobiotic-metabolizing enzymes. Mutat. Res. 380:43-59.

Tong SS, Y Hirokata, MA Trush, EG Mimnaugh, E Ginsburg, MC Lowe, TE Gram. 1981. Clara cell damage and inhibition of pulmonary mixed-function oxidase activity by naphthalene.

Biochem. Biophys. Res. Commun. 100(3):944-950.

Trainor KJ, DJ Wigmore, A Chrysostomou, JL Dempsey, R Seshadri, AA Morley. 1984. Mutation frequency in human lymphocytes increases with age. Mech. Ageing Devel. 27:8386.

U.S. Environmental Protection Agency (USEPA). 1991. Alpha2u-globulin: Association with chemically induced renal toxicity and neoplasia in the male rat. USEPA Risk Assessment Forum, Washington, DC.

U.S. Environmental Protection Agency (USEPA). 1998. Toxicological Review of Naphthalene (CAS No. 91-20-3) In Support of Summary Information on the Integrated Risk Information System (IRIS). U.S. EPA Office of Research and Development, Washington, DC. 
U.S. Environmental Protection Agency (USEPA). 2002. A Review of the Reference Dose and Reference Concentration Processes. EPA/630/P-02/002F. USEPA Risk Assessment Forum, Washington, DC.

U.S. Environmental Protection Agency (USEPA). 2003. Proposed OPPTS Science Policy: PPAR $\alpha$-Mediated Hepatocarcinogenesis in Rodents and Relevance to Human Health Risk Assessments. US EPA Office of Prevention, Pesticides \& Toxic Substances, Washington, DC.

U.S. Environmental Protection Agency (USEPA). 2004. Toxicological Review of Naphthalene (CAS No. 91-20-3) In Support of Summary Information on the Integrated Risk Information System (IRIS). NCEA-S-1707, June 2004, External review draft. U.S. EPA Office of Research and Development, Washington, DC.

U.S. Environmental Protection Agency (USEPA). 2005. Guidelines for Carcinogen Risk Assessment. EPA/630/P-03/001F. USEPA Risk Assessment Forum, USEPA, Washington, DC.

Waidyanatha S, MA Troester, AB Lindstrom, SM Rappaport. 2002. Measurement of hemoglobin and albumin adducts of naphthalene-1,2-oxide, 1,2-naphthoquinone and 1,4-naphthoquinone after administration of naphthalene to F344 rats. Chem. Biol. Interact. 141:189-210.

Ward JM, Uno H, Kurata Y, Weghorst CM, Jang J-J. 1993. Cell Proliferation not associated with carcinogenesis in rodents and humans. Environ. Health Perspect. 101(Suppl. 5):125-136.

Warren DL, DL Brown, AR Buckpit. 1982. Evidence for cytochrome P-450 mediated metabolism in the bronchiolar damage by naphthalene. Chem. Biol. Interact. 40:287-303.

West JA, AR Buckpitt, CG Plopper. 2000a. Elevated airway GSH resynthesis confers protection to Clara cells from naphthalene injury in mice made tolerant by repeated exposures. J. Pharmacol. Exp. Ther. 294(2):516-523.

West JAA, CH Chichester, AR Buckpitt, NK Tykler, P Brennan, C Helton, CG Plopper. 2000b. Heterogeneity of Clara Cell glutathione: A possible basis for differences in cellular responses to pulmonary cytotoxicants. Am. J. Respir. Cell Mol. Biol. 23:27-36.

West JA, G Pakehham, D Morin, CA Fleschner, AR Buckpitt, CG Plopper. 2001. Inhaled naphthalene causes dose dependent Clara cell cytotoxicity in mice but not in rats. Toxicol. Appl. Pharmacol. 173(2):114-119.

West JAA, LS Van Winkle, D Morin, CA Fleschner, HJ Forman, CG Plopper. 2003. Repeated inhalation exposures to the bioactivated cytotoxicant naphthalene (NA) produce airwayspecific Clara Cell tolerance in mice. Toxicol. Sci. 75:161-168.

Willems BAT, RL Melnick, MC Kohn, CJ Portier. 2001. A physiologically based pharmacokinetic model for inhalation and intravenous administration of naphthalene in rats and mice. Toxicol. Appl. Pharmacol. 176(2):81-91.

Wilson AS, Tingle MD, Kelly MD, Park BK. 1995. Evaluation of the generation of genotoxic and cytotoxic metabolites of benzo $(a)$ pyrene, aflatoxin $\mathrm{B}$, naphthalene and tamoxifen using human liver microsomes and human lymphocytes. Hum. Exp. Toxicol. 14:507-515.

Wilson AS, CD Davis, DP Williams, AR Buckpitt, M Pirmohamed, BK Park. 1996. Characterization of the toxic metabolite(s) of naphthalene. Toxicol. 114:233-242. 
Wolf O. 1976. Krebserkrankungen bei chemiearbeitern einer ehemaligen naphthalinreinigung. [Cancer diseases in chemical workers in a former naphthalene cleaning plant.] Dtsch. Gesundheits-Wesen. 31:996-999.

Wolf O. 1978. Arbeitshygiene und arbeitsschutz. [Industrial hygiene and industrial safety.] Z. Ges. Hyg. 24:737-739.

Wolfram S, 1999. The Mathematica Book, $4^{\text {th }} \mathrm{ed}$. Cambridge University Press, Cambridge, UK.

Yu D, JA Berlin, TM Penning, J Field. 2002. Reactive oxygen species generated by PAH oquinones cause change-in-function mutations in p53. Chem. Res. Toxicol. 15:832-842.

Zerban H, Radig S, Kopp-Schneider A Bannasch P, 1994. Cell proliferation and cell death (apoptosis) in hepatic preneoplasia and neoplasia are closely related to phenotypic cellular diversity and instability. Carcinogenesis 15:2467-2473.

Zheng Q. 1995. On the MVK stochastic carcinogenesis model with Erlang distributed cell life lengths. Risk Anal. 15:495-502.

Zheng J, M Cho, AD Jones, BD Hammock. 1997. Evidence of quinone metabolites of naphthalene covalently bound to sulfur nucleophiles of proteins of murine Clara cells after exposure to naphthalene. Chem. Res. Toxicol. 10(9):1008-1014. 